\title{
Annual Basis Carbon (ABC) Analysis of Biofuel Production at the Facility Level
}

John DeCicco and Rashmi Krishnan

University of Michigan Energy Institute

August 2015

University of Michigan Energy Institute

2301 Bonisteel Blvd., Ann Arbor, MI 48109-2100

energy.umich.edu 


\section{ACKNOWLEDGEMENTS}

This report was made possible through the support of the American Petroleum Institute (API) and the University of Michigan Energy Institute (UMEI). The analysis, results and conclusions presented here are those of the authors alone and the primary responsibility of the senior author, research professor John DeCicco of UMEI. The perspectives and views expressed here do not necessarily, and should not be taken to, reflect those of either API or UMEI. 


\section{Table of Contents}

EXECUTIVE SUMMARY

$\begin{array}{ll}\text { 1. INTRODUCTION } & 7\end{array}$

2. METHODS 9

2.1 Problems with biofuel LCA 9

2.2 Defining a testable method 11

2.3 Assessing net carbon uptake 16

3. ANALYSIS $\quad 18$

3.1 Carbon balance analysis on cropland $\quad 18$

3.2 GHG emissions of farm operations 20

3.3 Carbon balance and GHG emissions analysis of the biorefinery 21

3.4 GHG analysis of farm and refinery inputs 23

3.5 Coproduct and other displacement effects 24

3.6 End-use (motor vehicle) $\mathrm{CO}_{2}$ emissions analysis 25

3.7 Summation of pathway emissions 26

$\begin{array}{ll}3.8 \text { Sensitivity analysis } & 27\end{array}$

4. CONCLUSION

ENDNOTES

$\begin{array}{ll}\text { REFERENCES } & 33\end{array}$ 


\section{List of Tables and Figures}

\section{Tables}

1. Summary of direct annual basis carbon (ABC) flows 3

2. Carbon uptake on cropland 19

3. Farm on-site GHG emissions 21

4. Biorefinery carbon balance and on-site emissions 22

5. Farm and biorefinery off-site GHG emissions 24

6. Vehicle $\mathrm{CO}_{2}$ emissions 25

7. Summary of pathway and combined system ABC flows 26

8. Sensitivity to different cropland baseline assumptions 29

\section{Figures}

1. Schematic diagram for $\mathrm{ABC}$ analysis of motor fuel GHG impacts 2

2. Sensitivity of the GHG emissions increase to varying baseline assumptions 5

3. System boundaries as commonly defined for fuel lifecycle analysis (LCA) 10

4. Material carbon flows relevant to substitution of a biofuel for a fossil fuel 12

5. System boundary schematic for a unified biofuel and fossil fuel system 14

6. Carbon balance diagram for a generic system component 15

7. Carbon exchanges associated with an annual crop 16

8. U.S. average corn and soybean yields, 2000-2014 20 


\title{
Annual Basis Carbon (ABC) Analysis of Biofuel Production at the Facility Level
}

\author{
John DeCicco and Rashmi Krishnan
}

August 2015

\section{Executive Summary}

Liquid fuels derived from biomass have taken on increased importance over the years due to interests in expanding agricultural markets, energy security concerns and a need to reduce greenhouse gas (GHG) emissions. Biofuels are considered a form of renewable energy and the accounting conventions adopted to date for public policy treat biofuels as inherently carbon neutral, meaning that carbon dioxide $\left(\mathrm{CO}_{2}\right)$ from their combustion does not have to be counted because it is offset by $\mathrm{CO}_{2}$ uptake during feedstock growth. Thus, the prevailing wisdom has been that GHG accounting protocols only need to evaluate production-related emissions. The lifecycle analysis (LCA) methods used for the U.S. Renewable Fuel Standard (RFS) and California Low-Carbon Fuel Standard (LCFS) embed this carbon neutrality assumption.

However, results from LCA are highly variable, resulting in persistent disputes about the environmental impact of substituting a biofuel such as corn ethanol for a fossil fuel such as petroleum gasoline. LCA depends on major assumptions (including those regarding system boundaries) that cannot be empirically verified. Moreover, as applied to fuels to date, LCA does not correctly represent the terrestrial carbon cycle and so its use is particularly problematic for biofuels. Once substitution effects, including indirect land-use change (ILUC), are involved, the LCA paradigm requires projecting commodity market behavior and its results become not only highly uncertain but also scientifically untestable, erasing any hope that disputes might be eventually resolved through better data.

It would be useful to have an approach that can at least put clear bounds on fuel-related GHG impact estimates. Annual basis carbon (ABC) accounting is such a method because it tracks carbon flows on a strictly local basis one year at a time. It can be used to examine the GHG emissions impacts of substituting a biofuel for a fossil fuel that are directly tied to the fuels' physical supply chains. Unlike LCA, the ABC approach handles the carbon cycle correctly by explicitly estimating $\mathrm{CO}_{2}$ uptake as well as emissions. This report explains $\mathrm{ABC}$ accounting and applies it for a facility-level case study of substituting biofuel for fossil fuel. 


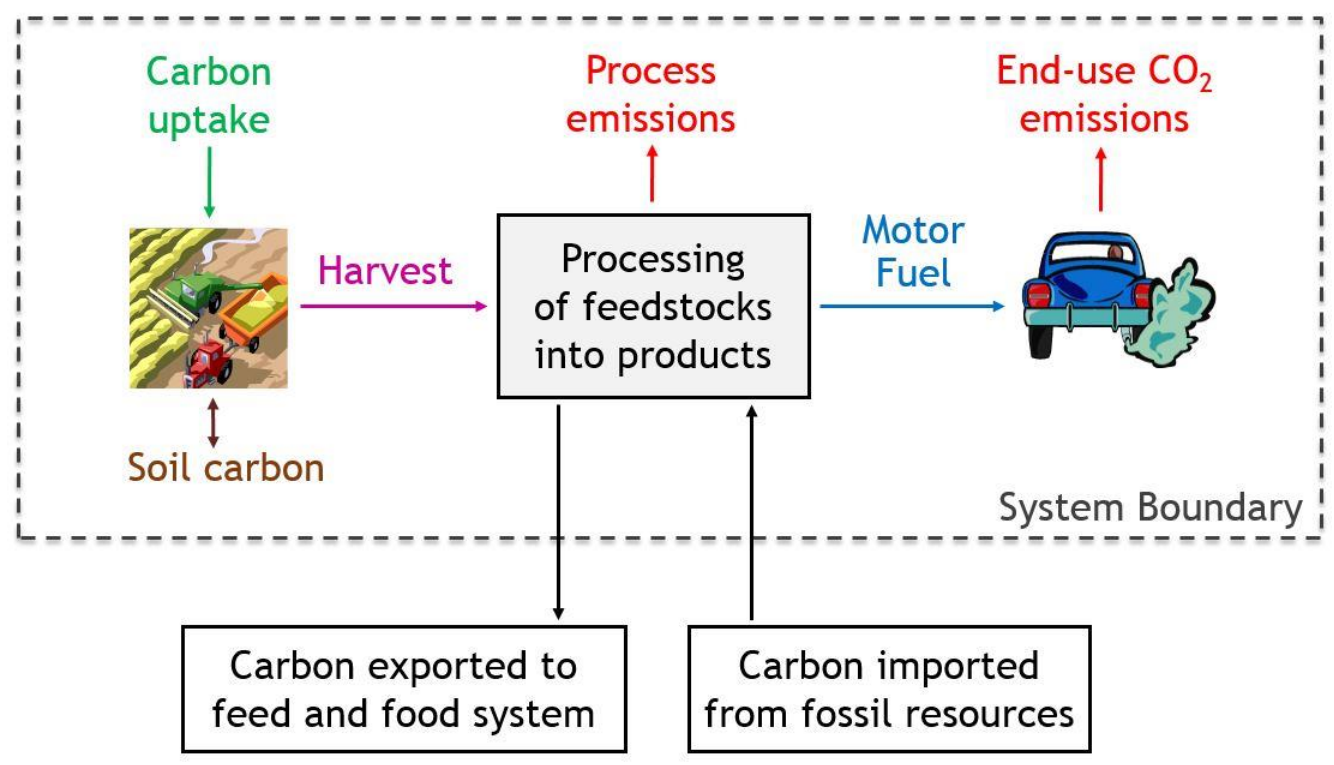

Figure 1. Schematic diagram for ABC analysis of motor fuel GHG impacts

A schematic diagram of the ABC method is shown in Figure 1. A crucial difference from LCA is the use of a single system boundary enclosing both the biofuel and fossil fuel supply chains. Rather than comparing distinct fuel product systems as does LCA, ABC analysis examines the GHG impact of a unified vehicle-fuel system from one year to the next, e.g., using gasoline in a baseline year and corn ethanol the following year. It is not a form of LCA and therefore does not yield carbon intensity $(\mathrm{CI})$ values $\left(\mathrm{gCO}_{2} \mathrm{e} / \mathrm{MJ}\right)$ for comparing fuels. Rather, ABC accounting tracks carbon and GHG flows for a circumscribed physical system under the use of one fuel or another. As also shown in the diagram, flows of fixed carbon (as opposed to $\mathrm{CO}_{2}$ ) are exported across the fuel system boundary in the form of biomass products (corn, soybeans and other agricultural products or coproducts) and are imported across the system boundary from fossil resources such as crude oil. Changes in these external flows result in displacement effects, such as reduced corn and soybean consumption in the food and feed system, which is partly offset by coproducts such as distillers' grains, and petroleum that remains unused by motor vehicles but which can induce a rebound effect in fuel markets.

Because it focuses on directly measurable GHG flows within the immediate fuel supply chains, the $\mathrm{ABC}$ method does not itself address displacements and other consequential effects outside the system boundary. The fate of carbon exported from the system circumscribed in 
Figure 1 is ultimately $\mathrm{CO}_{2}$ emissions from metabolism by animals and humans. There is some reduction of food system emissions due to the price effects of crop displacement and efficiencies that may be introduced through coproduct use, but there are also adverse emissions impacts due to land-use change. Prior studies show that the combined consequential effects, although highly uncertain in magnitude, serve only to increase a biofuel's net GHG emissions. Therefore, ABC accounting provides a lower bound on the overall GHG impact of using a biofuel rather than a fossil fuel.

To illustrate the method, we used data from a previously published LCA of a corn ethanol plant and its surrounding farmland. We examined the facility's first year of operation in 2007, when it produced 56 million gallons of ethanol, and made a before-and-after ABC comparison of replacing an energy-equivalent amount of gasoline with ethanol. In the baseline year, vehicles ran on petroleum gasoline while the farmland's harvest of corn and soybeans was exported to food markets. The following year, the same farmland grew only corn, all of which was used to produce ethanol that replaced gasoline. The ABC method then records a reduction of carbon exported from the system, which is partly compensated by the export of coproducts (distillers grains), as well as a reduction of carbon imported in the form of petroleum.

The results are summarized in Table 1 based on details given in the body of this report. The first line gives the carbon exchange on land, shown as a negative emission and reflecting the rate of net carbon uptake including biomass removed in the harvest plus any gain in soil carbon [units are thousand metric tons $\left(10^{6} \mathrm{~kg}\right)$ of carbon mass per year, $\mathrm{kt}_{\mathrm{c}} / \mathrm{yr}$ ]. The difference column

Table 1. Summary of direct annual basis carbon $(A B C)$ flows for a unified vehicle-fuel system using gasoline in a baseline year and corn ethanol the following year

\begin{tabular}{|c|c|c|c|}
\hline \multicolumn{4}{|c|}{ Carbon-equivalent mass flows, thousand metric tons per year $\left(\mathrm{kt}_{\mathrm{c}} / \mathrm{yr}\right)$} \\
\hline & $\begin{array}{r}\text { Year } 0 \text { using } \\
\text { gasoline }\end{array}$ & $\begin{array}{r}\text { Year }_{1} \text { using } \\
\text { ethanol }\end{array}$ & $\begin{array}{r}\text { Year }_{1}-\text { Year }_{0} \\
\text { Difference }\end{array}$ \\
\hline Carbon exchange on cropland & $(119)$ & $(189)$ & (70) \\
\hline Process emissions & 39 & 115 & 76 \\
\hline Vehicle emissions & 89 & 87 & $(2)$ \\
\hline Net emissions impact of the system & 10 & 14 & 4 \\
\hline Biomass carbon exported from system & 119 & 65 & $(53)$ \\
\hline
\end{tabular}


shows the change in carbon uptake; it is negative because the rate of carbon removal from the atmosphere by the cropland went up from the baseline year to the ethanol production year. The main reason for this large gain in uptake is a shift from growing soybeans on nearly half the cropland serving the facility to growing all corn when ethanol was produced; corn yields are higher than soybean yields, which means that a corn field removes more $\mathrm{CO}_{2}$ from the atmosphere than a soybean field. The second line gives process emissions, which are higher for ethanol production than for petroleum refining. These values are consistent with typical LCA estimates of the GHG emissions from feedstock and fuel processing, but for ethanol the ABC method also includes biogenic process emissions, notably the $\mathrm{CO}_{2}$ released during fermentation. Vehicle tailpipe $\mathrm{CO}_{2}$ emissions differ only slightly, with ethanol 2.2\% lower than gasoline.

Summing these values indicates that the net GHG emissions impact of the unified system (cropland, upstream and downstream processing and motor vehicles) is higher when ethanol is used than when gasoline is used. The difference is about 4 thousand metric tons of carbon per year $\left(\mathrm{kt}_{\mathrm{c}} / \mathrm{yr}\right)$, which in relative terms is $4.3 \%$ of the baseline $89 \mathrm{kt}_{\mathrm{c}} / \mathrm{yr}$ end-use $\mathrm{CO}_{2}$ emissions from gasoline use. This estimate is not a lifecycle ("well-to-wheels") CI metric, but simply the difference in direct GHG emissions from the circumscribed system of Figure 1 when using corn ethanol instead of gasoline. Although it is not directly comparable to an LCA-based CI value, the increase in direct GHG emissions found here contrasts sharply with the results of the previously published GREET analysis of the facility's first year of operation, which found a lifecycle CI for the corn ethanol that was $40 \%$ lower than that of gasoline.

The bottom row of Table 1 shows the changes in the rate at which carbon leaves the system in exported biomass. In the baseline year when gasoline is used, corn and soybeans are supplied to the external food system. When fuel ethanol is produced, only the coproducts are supplied to the food system. This large change in the supply of food-related biomass drives the displacement effects analyzed using the consequential modeling that has become part of LCA for fuels policy. For the case study examined here, the $53 \mathrm{kt}_{\mathrm{c}} / \mathrm{yr}$ loss of biomass exports represents $45 \%$ of the baseline $119 \mathrm{kt}_{\mathrm{c}} / \mathrm{yr}$ of exported biomass. Although not shown in the table, there is a reduction of $111 \mathrm{kt}_{\mathrm{c}} / \mathrm{yr}$ of fossil carbon imported into the system as petroleum. Nevertheless, this reduction of fossil fuel use does not result in a direct reduction of $\mathrm{CO}_{2}$ emissions because vehicle emissions do not significantly change. 


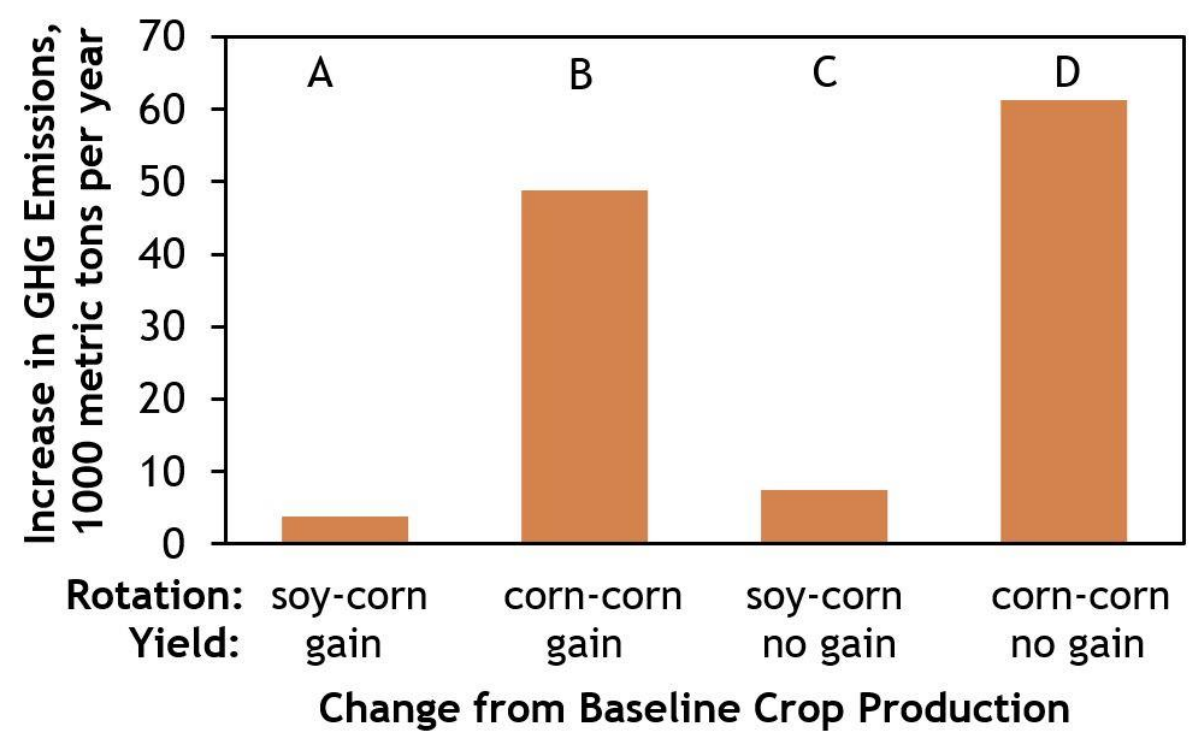

Figure 2. Sensitivity of the GHG emissions increase when using ethanol instead of gasoline to varying baseline assumptions regarding crop rotation and yield Source: Table 8

This analysis highlights the critical importance of baseline carbon uptake on the land from which a biofuel feedstock is sourced. In the LCA methods used for fuels policy, baseline carbon uptake is automatically and fully credited against tailpipe $\mathrm{CO}_{2}$ emissions, a modeling convention equivalent to assuming that uptake was zero before the feedstock was harvested for producing biofuel rather than for feed and food. But baseline carbon uptake is never zero on productive land and is in fact substantial for existing cropland, the main source of biofuels produced at commercial scale. For the facility analyzed here, a significant increase in carbon uptake occurred because of the shift from growing soybeans to growing corn on nearly half the cropland serving the facility.

A sensitivity analysis was conducted using different baseline conditions for crop rotation and yield, with the results shown in Figure 2. Case A is the actual first-year production situation, for which GHG emissions increased by $4 \mathrm{kt}_{\mathrm{c}} / \mathrm{yr}$ from the use of corn ethanol instead of gasoline (as given in Table 1). Case B represents the outcome if the baseline farm production had been all corn but there was still the gain in yield observed on the farmland serving the facility; in this case, emissions would have increased by $49 \mathrm{kt} / \mathrm{yr}$. Case $\mathrm{C}$ isolates the yield effect, which is much smaller than the crop rotation effect; without a yield gain, the emissions increase would have been $7 \mathrm{kt} / \mathrm{yr}$. Finally, Case D represents what the emissions impact would have been 
without either the shift from soy to corn or the gain in yield. In that case, there would have been no increase in carbon uptake on the farmland, and so the adverse emissions impact of producing and using ethanol is quite large. The increase in emissions calculated for Case $\mathrm{D}$ is $61 \mathrm{kt} / \mathrm{yr}$, implying that using corn ethanol would increase GHG emissions by nearly $70 \%$ compared to baseline tailpipe $\mathrm{CO}_{2}$ emissions using gasoline.

Case $\mathrm{D}$ is instructive because it reflects the situation closest to what is known about the general expansion of biofuel production from U.S. cropland. Although a national-scale ABC analysis awaits the results of future research, the shifts in crop production since the RFS was enacted have not been nearly so marked as the local, one-year shift of nearly half the farmland surrounding the case study facility from soy to corn. Moreover, although the additional corn demand to meet ethanol production requirements may induce a small additional gain in crop yield, such a gain would be incremental to the intrinsic yield trend underway though agricultural productivity improvements unrelated to ethanol production per se.

In summary, the biofuel carbon neutrality assumption built into LCA models does not hold up for real-world biofuel production. Direct accounting of actual carbon flows shows that, at best, corn ethanol production fails to reduce $\mathrm{CO}_{2}$ emissions relative to petroleum gasoline, and even that result depends on the gain in cropland carbon uptake that occurs with a large shift from growing soybeans to growing corn. If the baseline land use was corn production, then the increase in GHG emissions due to ethanol production would be significantly higher. Finally, if consequential effects including ILUC were to be included, the result would be a yet even higher estimate of the adverse net GHG emissions impact of biofuel use. 


\section{Introduction}

The net effects on carbon dioxide $\left(\mathrm{CO}_{2}\right)$ and other greenhouse gas (GHG) emissions due to the substitution of biofuel for petroleum fuel have been debated for many years. Most studies of this question have relied on lifecycle analysis (LCA) methods. Examples include the GREET model, ${ }^{1}$ which was developed by Argonne National Laboratory (ANL) for the U.S. Department of Energy (DOE) and has since been adapted by the California Air Resources Board (CARB) for administering the Low-Carbon Fuel Standard (LCFS). A more sophisticated LCA modeling system was developed by the U.S. Environmental Protection Agency (EPA) for administering the Renewable Fuel Standard (RFS). A premise of all such approaches is that diverse fuels can be quantitatively compared according to carbon intensity (CI) as calculated by evaluating GHG emissions over a given fuel's entire "well-to-wheels" ("cradle to grave") lifecycle. ${ }^{2}$

Scientifically speaking, the concept of fuel carbon intensity involves a major slippage in the meaning of the word "fuel." A fuel's lifecycle reflects a particular mental model of reality, i.e., it is an abstraction rather than a concrete physical property, defined by a feedstock-fuel system ("pathway") as imagined for purposes of analysis. Therefore, a CI value is the result of scenario modeling that depends on choices of an LCA method and analysis conventions as well as numerous parametric assumptions. These modeling choices are at least as influential in determining CI values as are the directly measured data available for the processes involved in producing a fuel, its feedstock, other inputs and associated effects. Thus, a CI is quite different from a physical property that can be reliably characterized using physiochemical data about a fuel substance itself and its components regardless of their origins and means of production. LCA incurs major challenges when analyzing biofuels, which involve consequential impacts such as indirect land-use change (ILUC) tied to dynamic effects that extend beyond the supply chain and play out many years into the future. Nevertheless, for many policy discussions and now for purposes of regulation, LCA-based CI values are treated as if they were physical properties analogous to, say, a fuel's sulfur content.

Ethanol from corn starch is the most widely produced biofuel in the United States and it now dominates global biofuel production as well. Ethanol is a partial substitute for petroleumderived gasoline and an important question is the extent to which such substitution offers a net reduction of GHG emissions. Analysts attempt to answer this question by comparing LCA-based 
CI values; however, even after many years of studies, no consensus has emerged on the answer. This unhappy situation should not be a surprise given the inherent uncertainties and critical nonempirical judgements involved in LCA. Many traditional, largely attributional lifecycle analysis (ALCA) studies found that corn ethanol decreases emissions relative to gasoline. ${ }^{3}$ The CI values adopted for the LCFS and RFS, based on more complex consequential lifecycle analysis (CLCA) methods, indicate that certain corn ethanol pathways have lower lifecycle GHG emissions than petroleum gasoline even after accounting for displacement effects and induced impacts such ILUC. Although the majority of current corn ethanol production is grandfathered under the RFS and so is not required to meet lifecycle GHG emissions criteria, EPA projects that corn ethanol from an average 2022 natural gas fired dry mill facility (similar to many recently built facilities) would have a CI that is $21 \%$ lower than that for baseline 2005 petroleum gasoline. ${ }^{4}$

Nevertheless, given the many assumptions involved in the modeling used to compute CI values, some analysts have concluded that the results are so uncertain that increased GHG emissions cannot be ruled out. ${ }^{5}$ Scientifically speaking, all such CI results are indeterminate; that is to say, they depend on assumptions (both structural and parametric) that cannot be verified empirically. ${ }^{6}$ The most problematic issues pertain to LCA model structure, including choices of system boundaries and the static nature of a lifecycle (since dynamic effects are integrated over the spatial and temporal boundaries of the lifecycle). ${ }^{7}$ Such concerns are especially challenging for CLCA, because time-varying effects are integrated over an arbitrary horizon (such as 30 years) and substitution effects are represented as averages (such as the displacement factors used for co-product calculations in GREET).

Given the irreducible uncertainties of LCA, it is fair to ask if another approach might be found that would be empirically testable. As long as the question is framed in a manner that requires a global system boundary, the answer is no. One might next ask: can the problem be bounded in a way that allows an empirical test, the results of which would constrain the GHG impact estimates with a relatively high degree of certainty? The answer then becomes yes. In fact, an empirically tractable approach is one that focuses on the part of a biofuel pathway most critical for carbon mitigation, namely, $\mathrm{CO}_{2}$ uptake during feedstock growth. A method termed annual basis carbon (ABC) accounting has been proposed for this purpose. ${ }^{8}$ It tracks carbon flows on a strictly local basis and one year at a time, examining a fuel supply chain in terms of its discrete components for which measurements of $\mathrm{CO}_{2}$ flows (uptake as well as emissions) and 
other GHG emissions can be obtained. This report summarizes an application of the ABC method for analyzing the corn ethanol produced at a particular facility for which a detailed LCA was previously published and to which the $\mathrm{ABC}$ results can be compared.

\section{Methods}

A truly empirical method will make use of all available data relevant to the question under investigation. Moreover, it can only look retrospectively at effects that have already occurred. These features are both points of contrast with the LCA methods that have been used to analyze fuel GHG impacts to date.

\subsection{Problems with biofuel LCA}

A biofuel lifecycle includes both the $\mathrm{CO}_{2}$ uptake in the biomass feedstock and the biogenic $\mathrm{CO}_{2}$ emitted when the fuel is burned plus any biogenic emissions within the supply chain, such as $\mathrm{CO}_{2}$ from fermentation during ethanol production. Within this conceptual model of the physical system, biogenic emissions are presumed to be completely offset by $\mathrm{CO}_{2}$ uptake, an assumption implemented in LCA models by either automatically crediting the offset during the calculations (as seen in GREET) or by simply omitting biogenic $\mathrm{CO}_{2}$ from the lifecycle tally.

Figure 2 gives a simplified schematic diagram illustrating how the LCA framework compares GHG emissions for fossil fuel and biofuel pathways. Emissions are assumed to result from steady-state process flows over the respective lifecycles; any dynamic effects, such as displacements or co-product substitutions, are modeled as averages over the assumed duration of the lifecycle. The top section illustrates a typical "well-to-wheels" fossil fuel cycle. The bottom illustrates a biofuel "field-to-wheels" lifecycle, showing how the biogenic $\mathrm{CO}_{2}$ is automatically credited. Each pathway is enclosed in its own distinct system boundary. Indirect emissions due to the release of terrestrial carbon stocks, as caused by ILUC, are shown within a dotted boundary because they are a result of market-induced effects outside the physical chain of fuel supply effects. ILUC is not shown for the petroleum fuel cycle because its magnitude is negligible relative to direct process and end-use emissions. ${ }^{9}$

Although arithmetically correct within the presumed equilibrium of a biofuel lifecycle, the biofuel carbon neutrality assumption is tautological rather than empirical. Thus, LCA models effectively disregard what are in fact the most certain data available, namely, $\mathrm{CO}_{2}$ emissions from fuel combustion. However, to determine the net emissions impact, such methods must then 
(a) PETROLEUM FUEL

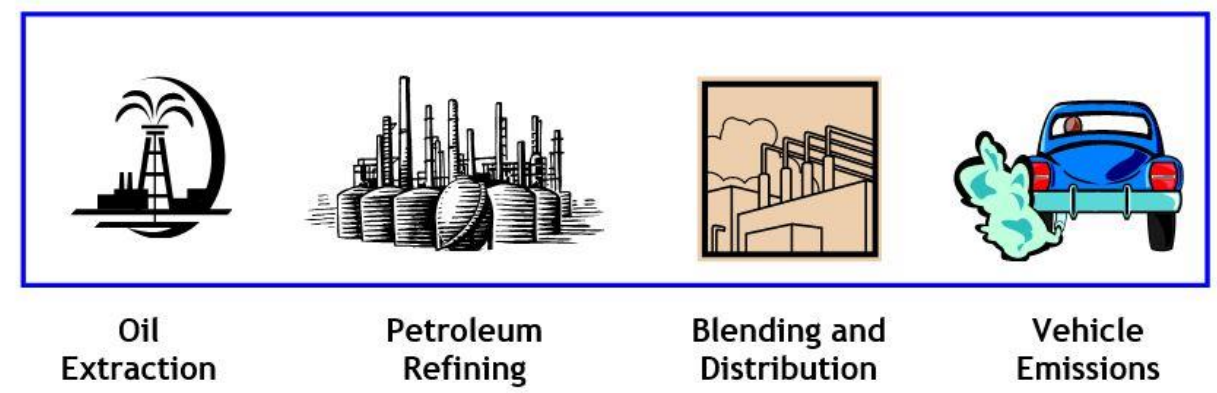

(b) BIOFUEL

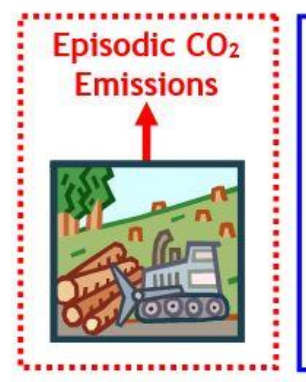

Indirect Land Use Change

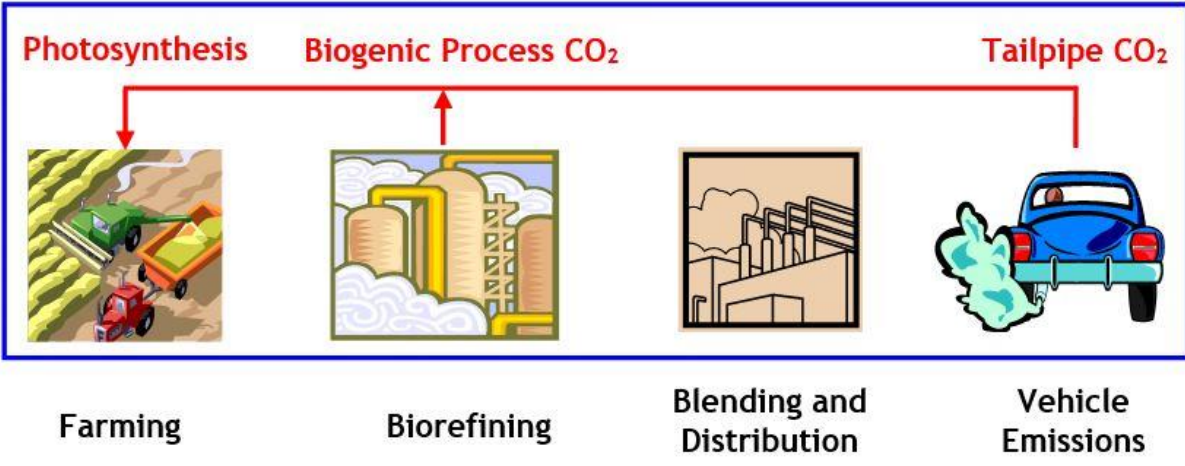

Figure 3. System boundaries as commonly defined for fuel lifecycle analysis (LCA)

resort to modeling consequential effects for which limited and highly uncertain data exist, and which requires assumptions about future terrestrial carbon cycle impacts for which data of course do not exist. LCA therefore fails on two counts: it omits highly relevant available data and it relies on projections that cannot be validated. In other words, the method creates a misplaced burden of proof by presuming that biofuels are inherently carbon neutral and then requiring a highly uncertain and in fact untestable analysis of the extent to which net $\mathrm{CO}_{2}$ reduction is actually achieved.

Another problem with LCA is that, even if it attempts to address dynamic effects, it averages them over the spatial and temporal boundary of the system, thereby representing a fuel pathway as being in equilibrium over its lifecycle. Comparing a biofuel to a fossil fuel, as illustrated in Figure 2, then amounts to comparing two distinct quasi-steady-state process flows. Such an approach fails to capture two critical aspects of real-world system dynamics. First of all, the biosphere is not in equilibrium with the atmosphere to begin with; its carbon exchanges involve a stock-and-flow interaction with ongoing positive and negative $\mathrm{CO}_{2}$ flows and carbon stocks with varying time constants, including long-term stocks in standing biomass and soils. 
Second, the very act of substituting a biofuel for a fossil fuel involves dynamic changes in the rates and locations of carbon flows in the coupled bio- and fossil-fuel system. Thus, LCA's stylized approach of comparing distinct steady-flow systems invokes a flawed model of reality, risking results that are not only very uncertain but also erroneous.

\subsection{Defining a testable method}

To find an approach that both reflects real-world dynamics and is testable empirically, one must first consider the data available for estimating the effects most important for carbon mitigation. Because phenomena can only be directly measured at specific locations and times, the method must be spatially explicit and temporally constrained (i.e., up to the most recently available data, rather than relying on projections). Annual basis carbon (ABC) accounting follows this principle by relying on location-specific data evaluated one year at a time.

In an $\mathrm{ABC}$ approach, end-use emissions are explicitly tallied for all fuels. These direct (tailpipe) $\mathrm{CO}_{2}$ emissions are the aspect of a fuel pathway for which the most certain data are available. Liquid fuels that substitute for one another vary little in terms of $\mathrm{CO}_{2}$ released per unit of energy delivered, and so it is clear that the downstream locations where fuel substitution occurs are not the locations where fuel-related emissions reductions are found. If any mitigation occurs, it happens in locations of $\mathrm{CO}_{2}$ uptake, namely, on the land where feedstocks are grown. Therefore, a testable approach must examine data that enable estimation of $\mathrm{CO}_{2}$ flows on the cropland from which biofuel feedstocks are sourced. Emissions must also be assessed at other locations in the fuel supply chain, which is the portion of GHG accounting that LCA methods are designed to handle. Nevertheless, understanding the ABC approach requires setting aside the LCA paradigm of tracing material flows through a supply chain and the commodity systems with which it interacts. One must focus instead on the direct GHG flows (including the all-important downward flow of $\mathrm{CO}_{2}$ from the atmosphere into biomass) exactly where and when they occur.

What one gives up in an $\mathrm{ABC}$ approach is the ability to estimate economically induced impacts such as substitution effects in commodity markets and associated consequences such as ILUC. But because ABC accounting evaluates the direct carbon balance impacts of biofuel and fossil fuel pathways, it enables an empirical test of the extent to which any emissions-mitigating net carbon uptake occurs in the biofuel pathway. The cumulative impacts of coproduct substitutions, fuel market rebound and other displacement effects including ILUC serve only to increase overall GHG emissions impact of biofuel use. ${ }^{10}$ Therefore, if the threshold results from 


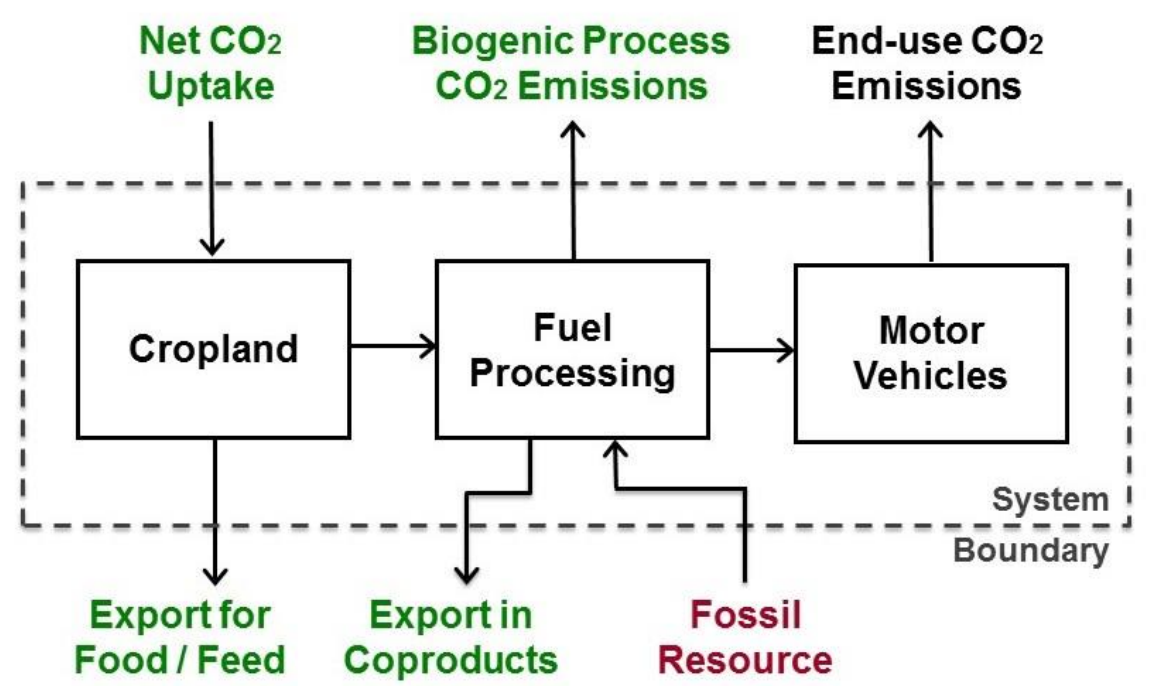

Figure 4. Material carbon flows relevant to analyzing the substitution of a biofuel for a fossil fuel

$\mathrm{ABC}$ analysis fail to show a decrease, then the net impact will be either the same or higher GHG emissions overall.

For analyzing the substitution of a liquid biofuel for a fossil fuel (such as corn ethanol for petroleum gasoline), what are most critical are the material carbon flows associated with the fuel itself, referring to the molecular carbon that originates in the feedstock, as opposed to the $\mathrm{CO}_{2}$ and other GHG emissions related to processing inputs. The latter must be tracked of course, as they are in LCA, but the extent to which end-use (tailpipe) $\mathrm{CO}_{2}$ emissions are balanced by $\mathrm{CO}_{2}$ uptake is a matter of the material carbon flows, which are depicted in Figure 4. This diagram is a variant of Figure 1 highlighting the carbon flows that are a subset of the overall GHG flows. As in Figure 1, the Figure 4 schematic defines a single system boundary across which the material carbon flows are evaluated. Cropland is always within the system boundary and so carbon removal from the atmosphere is counted whether or not the carbon in the fuel carbon originates from cropland or a fossil resource.

The flows along the top of the diagram are direct $\mathrm{CO}_{2}$ exchanges between the physical feedstock-fuel system and the atmosphere; the flows along the bottom are movements of some form of fixed carbon, either in biomass leaving the system or crude oil entering it. Because enduse emissions are independent of the origin of the material carbon in the motor fuel, the net $\mathrm{CO}_{2}$ 
flow to the atmosphere from the circumscribed system can only be decreased by increasing the rate of $\mathrm{CO}_{2}$ uptake on the cropland. Changes in carbon exports, which for a corn feedstock flow into the food system (including livestock), can affect $\mathrm{CO}_{2}$ and other $\mathrm{GHG}$ emissions in the broader external system. Given the inelasticity of food demand, a reduction of biomass carbon from a given area of cropland will be largely made up by obtaining biomass from other cropland (whether through intensification or expansion), resulting in little change in food consumption and therefore little change in $\mathrm{CO}_{2}$ emitted when food is metabolized.

Thus, a core part of $\mathrm{ABC}$ accounting for biofuel use is estimating the carbon exchanges across the system boundary shown in Figure 4. In addition to those material carbon flows, the emissions from the associated production processes are estimated in a manner similar to what is done in LCA. Because the necessary data can be calculated directly from measurable physical quantities and process energy use, the net GHG balance of the circumscribed vehicle-fuel system can be estimated with a high degree of certainty. Comparing the GHG balance when using the biofuel to that when using the fossil fuel yields a lower bound estimate of the GHG emissions impact of the substitution. Projecting the consequential impacts of the changes in carbon exported from the system greatly raises the uncertainty of the overall impact, but the sign of those effects can only be positive (i.e., serving to increase emissions).

To complete the aspects of an $\mathrm{ABC}$ analysis that are directly comparable to a traditional ALCA, one adds the emissions associated with the other supply chain components shown in Figure 3 to the material carbon flows illustrated in Figure 4. The resulting set of components to be analyzed within a single system boundary is shown in Figure 5. Although the accounting is organized differently than LCA, it is conceptually straightforward and simply involves adding up GHG emissions at the discrete physical locations within the circumscribed bio- and fossil fuel production and use system to be analyzed. In this regard, an ABC approach adheres to a standard methodology that was developed for the International Energy Agency (IEA), ${ }^{11}$ a critical feature of which is a consistently defined single system boundary that includes all components of both the biofuel and fossil fuel pathways. The two pathways are analyzed as subsystems of single system that operates differently when one fuel is use instead of another, rather than analyzed as separate systems under an LCA approach as depicted in Figure 3.

For simplicity, Figure 5 shows only the major components of the respective biofuel and petroleum fuel subsystems as well as the downstream locations up to and including end-use fuel 


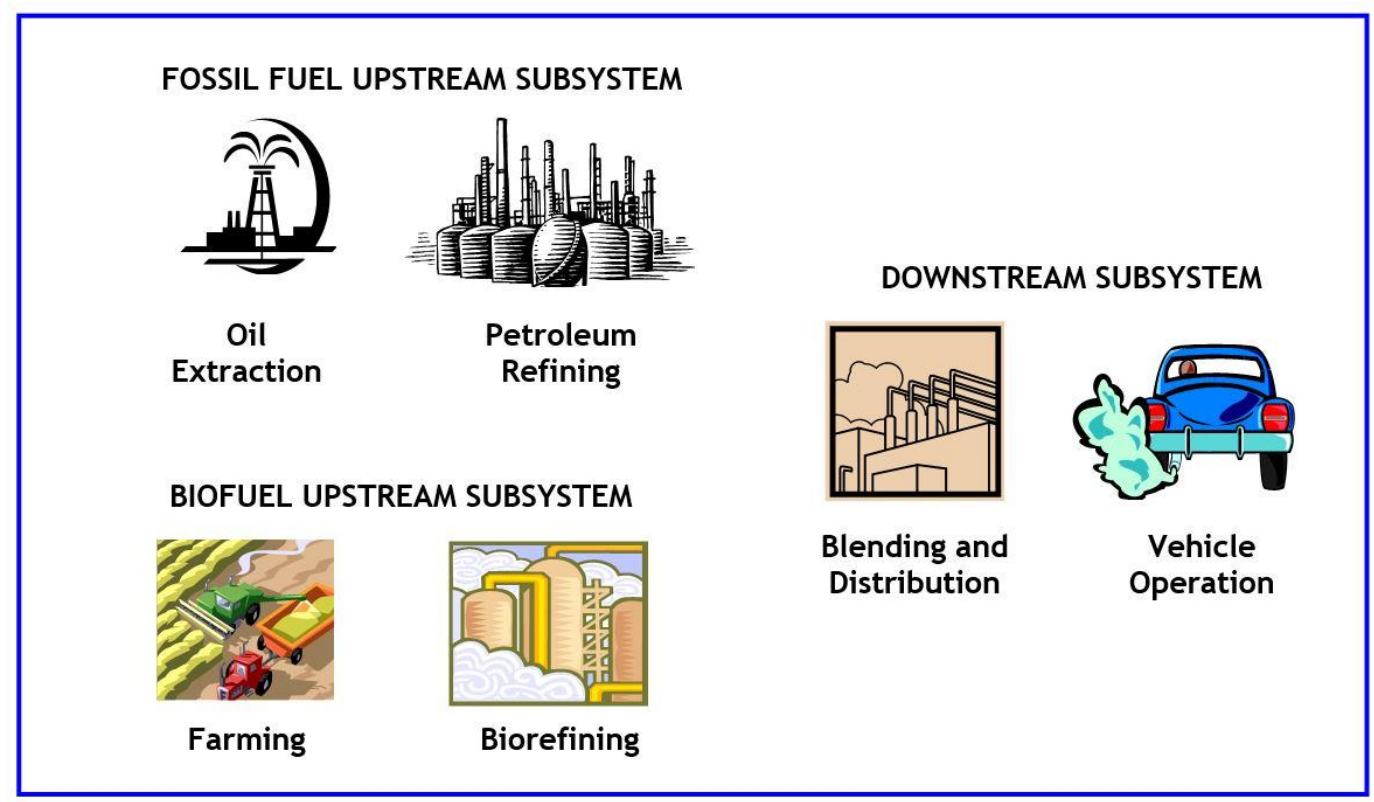

Figure 5. System boundary for a unified biofuel and fossil fuel production and use system

combustion in motor vehicles. The basic step of an $\mathrm{ABC}$ accounting is to compare the inputs and outputs of the unified system from one year to the next. The analysis is fully localized spatially and temporally, meaning that it entails discrete annual carbon balance estimations for each component of the unified system. The major analytic steps for the biofuel subsystem ("pathway") include:

1. Carbon balance on the cropland

2. GHG emissions of farm operations

3. Carbon balance and GHG emissions analysis of the biorefinery

4. GHG analysis of farm and biorefinery inputs (fertilizer, purchased energy)

5. Carbon balance of coproducts and other biomass displacements

6. End-use (motor vehicle) $\mathrm{CO}_{2}$ emissions analysis

Analogous calculations are carried out for the petroleum fuel pathway. Summing the emissions from each step yields pathway subtotals, which are then added together to calculate the total net emissions for the unified system. It is such totals that we report; they represent the change in net GHG emissions directly associated with the unified fuel production and use system, including upstream emissions for system inputs such as electricity, natural gas, tractor fuel, fertilizer, etc. Displacement effects due to changes in non-fuel material flows (such crops not used for fuel or 


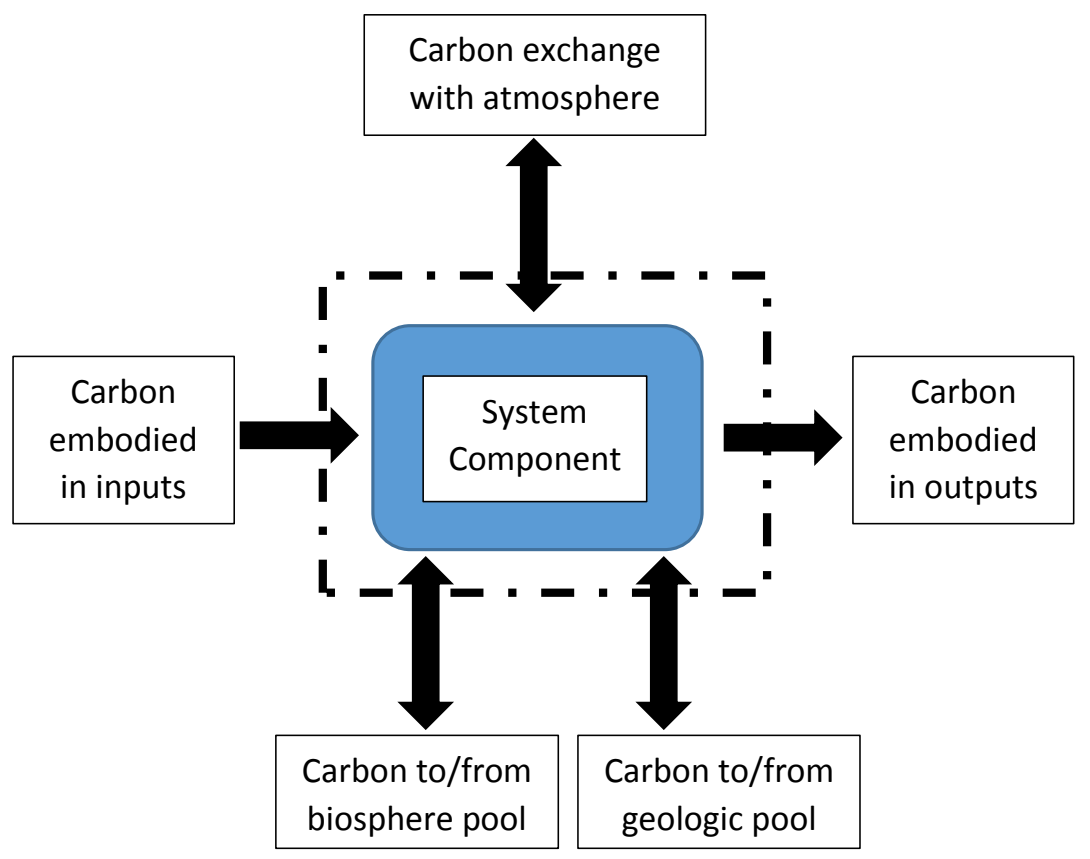

Figure 6. Carbon balance diagram for a generic system component

coproducts used for feed) are excluded from the summation; the changes in such quantities of carbon are reported as balance terms.

A schematic of a component-level carbon mass balance is shown in Figure 6, which conveys the generic elements of the ABC method. Not all components have every type of interaction; for example, the biorefinery does not interact directly with the biosphere. Below we will specifically illustrate the component-level interactions for cropland. In addition to the carbon that enters a system component in either material inputs or fuel, component processes may use inputs that do not physically contain carbon, such as electricity or nitrogen fertilizer. The upstream emissions associated with such inputs are calculated separately based on emissions factors as discussed in Section 3.4 below. Although supply chain components are related through their inputs and outputs as well as process and market dynamics, these discrete component-level tallies are additive. The GHG flows to or from the atmosphere for each component can then be summed to calculate the net emissions impact of the system.

For evaluating the effect of ethanol production and use ramping up from one year to next, the system is first evaluated in a baseline year $(\mathrm{t}=0)$ without corn ethanol production and with vehicles using gasoline. It is then evaluated in a subsequent year $(t=1)$ with ethanol substituting for the gasoline. Comparing the results for the two years yields an estimate of the change in 
direct GHG emissions (i.e., emissions directly from the physical production and consumption system) due to the fuel substitution. $\mathrm{ABC}$ accounting results are not lifecycle impact projections and cannot be reduced to a $\mathrm{CI}$ metric such as a $\mathrm{gCO}_{2} \mathrm{e} / \mathrm{MJ}$ value generated by LCA models. ABC results are given on a carbon mass flow basis, e.g., metric tons per year $\left(t_{c} / y r\right)$ and should not be viewed as an attribute of a particular fuel pathway but rather seen as the GHG impact of a unified biofuel and fossil fuel system operating under different conditions.

\subsection{Assessing net carbon uptake}

Productive land is constantly exchanging carbon with the atmosphere. $\mathrm{CO}_{2}$ is absorbed during photosynthesis and is subsequently emitted by respiration, which is the release of $\mathrm{CO}_{2}$ from biochemical oxidation processes through which organisms use organic material for metabolism. For annual crops such as the corn or soybeans used for either food or biofuel production, the production of biomass for harvest represents a substantial net movement of carbon as $\mathrm{CO}_{2}$ from the atmosphere to organic carbon fixed in biomass.

The carbon exchanges associated with a crop are illustrated in Figure 7. A single corn plant is shown, but the terms are similar for any annual crop and can be evaluated over any area of cropland. The total amount of carbon fixed by plants on a net basis is termed net primary production (NPP), often measured as metric tons of carbon per hectare per year. ${ }^{12}$ Broadly speaking, this carbon ends up in one of three places. ${ }^{13}$ A good portion ends up in the harvest $(\mathrm{H})$,

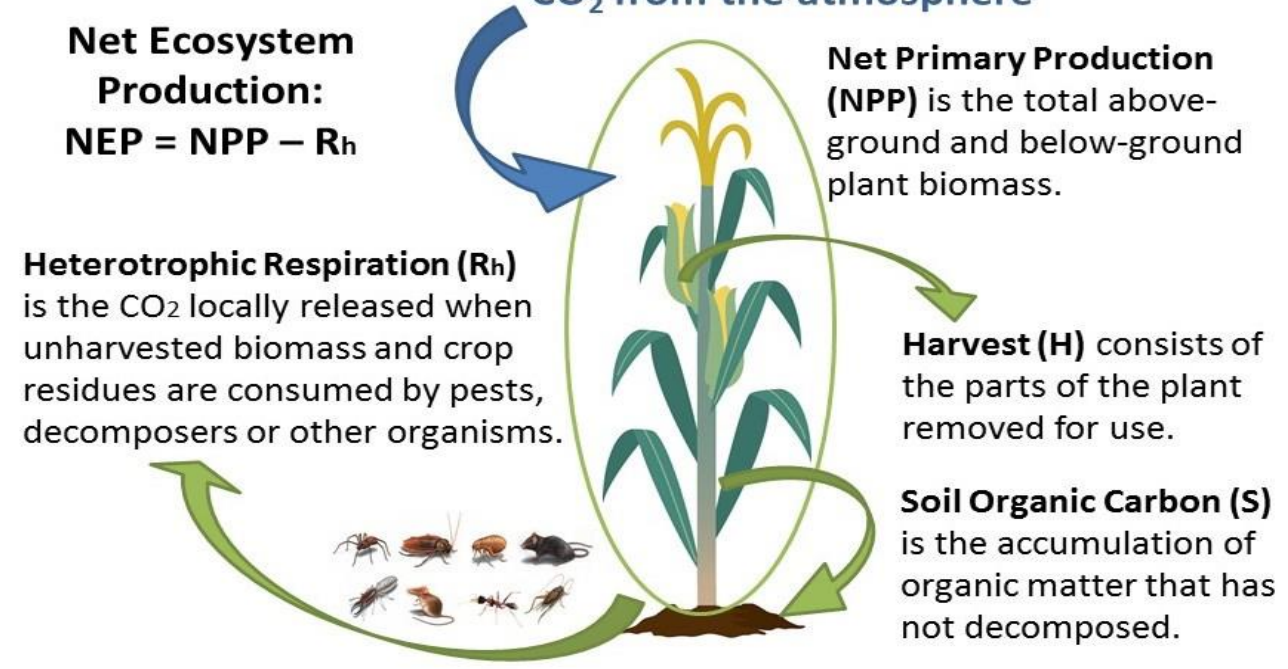

Figure 7. Carbon exchanges associated with an annual crop Image Credit: Jane Thomas, Integration and Application Network, University of Maryland Center for Environmental Science (ian.umces.edu/imagelibrary/) 
which is removed from the cropland for use in other locations. A small portion may accumulate in the ground as soil organic carbon (SOC; shown as simply $\mathrm{S}$ in the figure). For most crops, a large part remains behind to decompose or otherwise be consumed by insects and other organisms on the land; this portion is termed heterotrophic respiration $\left(\mathrm{R}_{\mathrm{h}}\right)$ and represents the $\mathrm{CO}_{2}$ that is locally re-released into the atmosphere.

The difference between NPP and $R_{h}$ is termed net ecosystem production (NEP), which is the amount of carbon fixed in the biosphere and potentially available for some use. ${ }^{14}$ Also called net ecosystem exchange (NEE), ${ }^{15}$ NEP represents to the net flow of carbon from the atmosphere into the biosphere over a given area of land. It can be evaluated for any land area up to and including the entire globe. For ABC accounting, NEP is evaluated locally, i.e., on a spatially explicit basis, over the area of land from which biomass feedstocks are harvested. Referencing Figure 7, a carbon mass balance implies that NEP can be derived from data on the quantity of biomass harvested and estimates of soil carbon accumulation:

$$
\mathrm{NEP}=\mathrm{H}+\mathrm{S}
$$

These variables are all annual mass flows; on an area basis they would correspond to carbon fluxes. As was shown in Figure 3, net $\mathrm{CO}_{2}$ uptake is the key material carbon flow of interest for evaluating biofuel production, and it can be determined by estimating NEP.

Formal stock-and-flow analysis shows that for a biofuel to potentially offer a net reduction in $\mathrm{CO}_{2}$ emissions, even before considering process emissions, its production must result in a gain in NEP; i.e., an increase in the rate of net carbon uptake. ${ }^{16}$ This requirement formalizes the Searchinger (2010) insight regarding "the need for additional carbon" and it can be written as:

$$
\mathrm{d}(\mathrm{NEP}) / \mathrm{dt}>0
$$

In other words, there must be an acceleration of the net flow rate of $\mathrm{CO}_{2}$ from the atmosphere into the biosphere associated with the production of the biofuel's feedstock. This condition can be evaluated over a time step of one year by calculating:

$$
\Delta \mathrm{NEP}_{\mathrm{t}}=\mathrm{NEP}_{\mathrm{t}}-\mathrm{NEP}_{\mathrm{t}-1}
$$

where $t$ is an annual time index. If $\triangle \mathrm{NEP}_{\mathrm{t}}$ is positive, it represents additional carbon uptake that can be credited against biogenic $\mathrm{CO}_{2}$ emissions from biofuel combustion and processing. 


\section{Analysis}

This facility-level case study is based on a previously published GREET analysis of a particular corn ethanol plant and an accompanying analysis of land use in the farm area serving the plant (Mueller et al 2008a,b; hereinafter referred to as the IRE reports). The plant is the Illinois River Energy (IRE) facility located in Rochelle, IL. It is a natural gas fired dry mill corn ethanol biorefinery that began full operation in 2007 and is currently owned by CHS, Inc., a diversified energy and agricultural products company. ${ }^{17}$ The IRE facility has a rated production capacity of 130 million gallon per year (5,600 bbl/day gasoline equivalent) and during the first year of its operation, in 2007, it produced 56 million gallons $\left(4.5 \times 10^{15} \mathrm{~J}\right)$ of anhydrous ethanol. ${ }^{18}$

Examining the first year of operation enables us to compare the carbon flows when fuel ethanol was produced to those that took place during the prior year without ethanol production, providing a direct estimate of the change in NEP and associated GHG emissions. That analysis is summarized below, with additional details on the data and parameters provided in an Excel workbook available upon request. As a point of comparison, the IRE report's GREET analysis estimated that the ethanol produced during the facility's first year of operation had a CI of 54.8 $\mathrm{gCO}_{2} \mathrm{e} / \mathrm{MJ}$, or $40 \%$ lower than the $92.1 \mathrm{gCO}_{2} \mathrm{e} / \mathrm{MJ} \mathrm{CI}$ of petroleum gasoline calculated at the time. More recent analyses of the same and similar biorefineries have calculated even lower corn ethanol CI values using updated versions of GREET that reflect ongoing efficiency gains for ethanol production. ${ }^{19}$ However, such data and parameter updates do not address the fundamental carbon cycle issues that motivate the present analysis.

\subsection{Carbon balance analysis on cropland}

To relate above equations to agricultural data, let $\mathrm{H}_{\mathrm{ijt}}$ denote the carbon embodied in the harvest of crop $i$ from a parcel of land $j$ in year $t$. Given harvest data in bushels, biomass composition data can be used to compute $\mathrm{H}_{\mathrm{ijt}}$ in units of carbon mass. The quantity of harvest depends on crop rotations as well as land going in or out of production; it is zero for land not in production. For annual crops and no double cropping, $\mathrm{H}_{\mathrm{ijt}}>0$ only for the single crop $i$ harvested in year $t$; it would be non-zero for two crops (two different values of $i$ ) for double cropping. Soil carbon is also indexed as $\mathrm{S}_{\mathrm{ijt}}$ because it depends on the particular crop grown on a given parcel of land.

Substituting the variables representing the cropland data into Equations (1) and (3) and summing over crops and land yields the formula for evaluating the annual change in NEP: 
Table 2. Carbon uptake on cropland

\begin{tabular}{|lrrr|}
\hline \multicolumn{5}{|c|}{ Net Ecosystem Production (NEP) } & in metric tons per year on a carbon mass basis $\left(\mathrm{t}_{c} / \mathrm{yr}\right)$ \\
Item & Year $\mathbf{0}$ & Year $\mathbf{1}$ & $\Delta \mathrm{NEP}$ \\
\hline $\mathrm{C}$ in corn harvest & $(88,888)$ & $(188,075)$ & \\
$\mathrm{C}$ in soy harvest & $(29,727)$ & - & \\
$\mathrm{C}$ in total harvest & $(118,615)$ & $(188,075)$ & \\
$\Delta$ SOC & & $(600)$ & \\
\hline Total for cropland serving the IRE facility & $\mathbf{( 1 1 8 , 6 1 5 )}$ & $\mathbf{( 1 8 8 , 6 7 5 )}$ & $\mathbf{( 7 0 , 0 6 0 )}$ \\
\hline
\end{tabular}

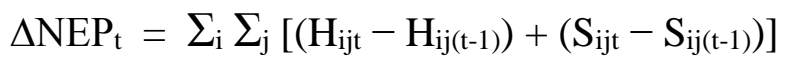

For the case study described here, this change in NEP is evaluated over a single year, comparing the NEP on the cropland serving the facility during its first year of operation (Year 1) to the NEP on the same cropland in the prior year (Year 0).

The resulting estimates are shown in Table 2; they are shown as negative numbers because the sign convention treats emissions into the atmosphere as positive. The values were derived from crop rotation data provided in the IRE report, with the parcels of land ( $j$ index) defined by the areas harvested for the two years analyzed according to reported rotation pattern (49\% soy-corn, $51 \%$ corn-corn). The NEP estimates are essentially determined by the carbon in the harvested biomass, which amounted to a downward flow of carbon from the atmosphere to the biosphere at the rate of roughly 119 thousand metric tons per year $\left(\mathrm{kt}_{\mathrm{c}} / \mathrm{yr}\right)$ in Year 0 and roughly $189 \mathrm{kt}_{\mathrm{c}} / \mathrm{yr}$ in Year 1.

The IRE report treats soil organic carbon (SOC) only as the change in sequestration due to the shift in crops planted for the first year of operation rather than providing annual values of the soil carbon flux. As is typical for annual crops, the portion of NEP accounted for by changes in soil carbon is quite small, e.g., amounting to $0.3 \%$ of the carbon embodied in the harvest for the IRE area cropland. ${ }^{20}$ Table 2 shows a value only for Year 1, with $\Delta$ SOC including the gain in soil carbon due to the soy-corn rotation net of a nearly negligible carbon release due to DLUC. Based on the IRE local land-use study, ${ }^{21}$ only a very small amount of direct land-use change (DLUC) was seen from Year 0 to Year 1.

The most notable revelation of this calculation is the large gain in NEP from growing corn instead of soy. Corn is one of the most photosynthetically productive of all plants, and it has been bred to have a very high grain yield; roughly half of the annual plant growth by mass is in 


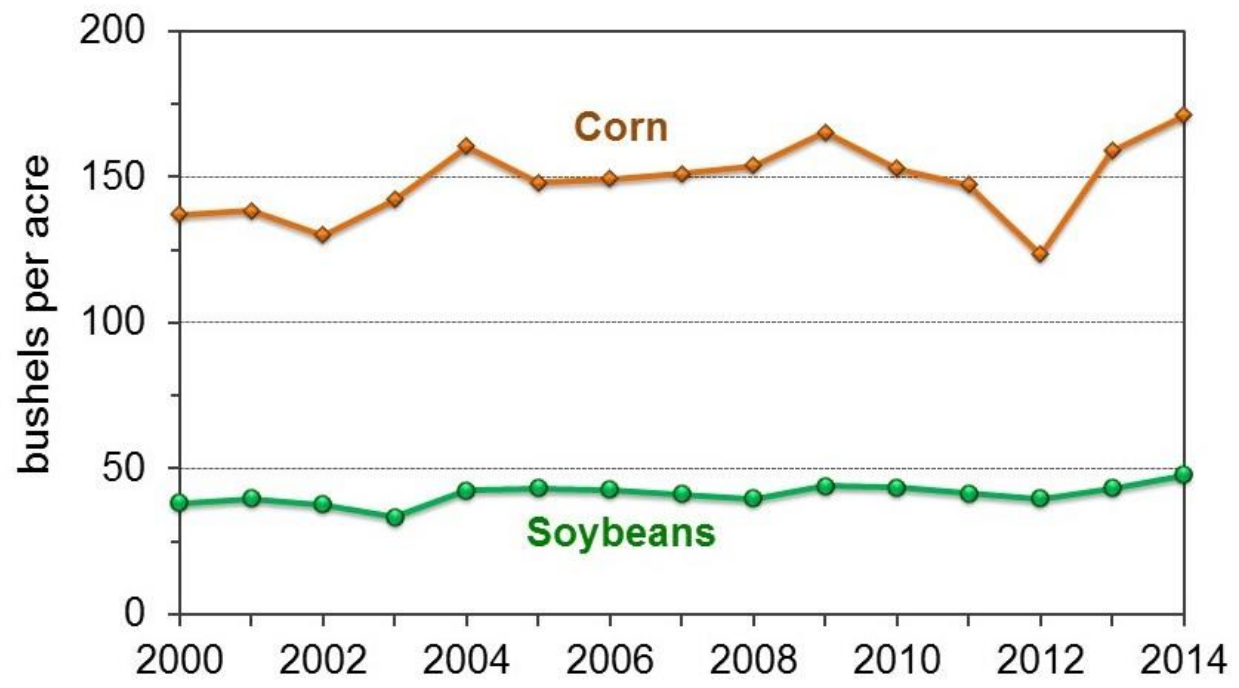

Figure 8. U.S. average corn and soybean yields, 2000-2014

Source: http://www.nass.usda.gov/Quick_Stats/ accessed 28 May 2015

the corn kernels, so only half the biomass ends up as residue. This high productivity is reflected in the yield statistics as shown in Figure 8; recent corn yields have averaged around 150 bushels per acre (bu/a) compared roughly $45 \mathrm{bu} / \mathrm{a}$ for soybeans nationally. Illinois corn yields are often much higher than the national average.

The last column of Table 2 shows that the increase in NEP over the first year amounted to $70 \mathrm{kt} / \mathrm{yr}$. A small portion of the gain was from better yields, which locally went from $183 \mathrm{bu} / \mathrm{a}$ in 2006 to 196 bu/a in 2007 (a 7\% increase) according to the IRE report. Thus, the vast majority of the increase in NEP was a result of growing corn instead of soybeans on $49 \%$ of the land. A carbon uptake gain of this magnitude would not occur if the farmland previously grew only corn, a situation that will be examined as a sensitivity case.

\subsection{GHG emissions of farm operations}

This part of the analysis is similar to that of conventional LCA for the emissions sources located on the farm itself, such as fuel burned for tractors and drying equipment, $\mathrm{N}_{2} \mathrm{O}$ from the cropland and any other local emissions of significance. Under $\mathrm{ABC}$ accounting, these sources fall inside the unified system boundary and are therefore tallied regardless of the level of renewable fuel production. Because these are strictly on-site emissions, upstream emissions associated with producing fertilizer, tractor fuel and other farm inputs are handled separately as part of the offsite tally described in Section 3.4 below. 
Table 3. Farm on-site GHG emissions

\begin{tabular}{|l|r|r|}
\hline \multicolumn{3}{|c|}{ Metric tons carbon mass-equivalent per year $\left(\mathrm{t}_{\mathrm{c}} / \mathrm{yr}\right.$ ) } \\
\hline & Year 0 & Year 1 \\
\hline Tractor and other farm operational fuel use & 2,192 & 3,144 \\
$\mathrm{~N}_{2} \mathrm{O}$ from fertilizing corn fields (carbon equiv) & 8,858 & 17,499 \\
$\mathrm{~N}_{2} \mathrm{O}$ from fertilizing soybean fields (carbon equiv) & 346 & 0 \\
\hline Total farm on-site GHG emissions & $\mathbf{1 1 , 3 9 5}$ & $\mathbf{2 0 , 6 1 4}$ \\
\hline
\end{tabular}

Using farm fuel use data and fuel-specific direct (end-use) $\mathrm{CO}_{2}$ emissions factors yields values shown in the first row of Table 3, reflecting the somewhat larger on-farm fuel use when growing corn rather than soybeans. The Year 1 estimate of 3,144 $t_{c} / y r$ was derived from data provided in the IRE report. The Year 0 estimate was derived by prorating the Year 1 value with the ratio of on-farm fuel consumption for soy and corn farming from Hill et al (2006) and the fact that $49 \%$ of the land was planted with soybeans that year.

\subsection{Carbon balance and GHG emissions analysis of the biorefinery}

The biorefinery calculations will have two parts, one representing the carbon mass balance of the biomass feedstocks and resulting products and the other representing GHG emissions due to nonbiomass energy use. The carbon mass balance calculation is given by

$$
\mathrm{M}_{\text {in }}=\mathrm{M}_{\text {prod }}+\sum_{\mathrm{k}} \mathrm{M}_{\mathrm{k}}+\mathrm{M}_{\mathrm{burn}}+\mathrm{M}_{\mathrm{loss}}
$$

where $k$ is an index over one or more co-products (such as distillers' grains) and the equation is in units of carbon mass. $M_{\text {in }}$ is the quantity of carbon embodied in the feedstock and based on the amount of harvest delivered to the biorefinery. $\mathbf{M}_{\text {prod }}$ is the carbon mass of the fuel product, e.g., the carbon contained in the anhydrous ethanol produced by an ethanol facility. $M_{k}$ is the mass of carbon in a co-product. $\mathrm{M}_{\text {burn }}$ and $\mathrm{M}_{\text {loss }}$ represent carbon derived from the biomass feedstock and emitted as biogenic $\mathrm{CO}_{2}$ at the biorefinery. Their sum represents the portion of the molecular carbon from the feedstock that flows into the atmosphere at the location of the biorefinery:

$$
\mathrm{M}_{\text {bio }}=\mathrm{M}_{\text {burn }}+\mathrm{M}_{\text {loss }}
$$

Under $\mathrm{ABC}$ accounting, this $\mathrm{CO}_{2}$ release is explicitly counted, in contrast to the LCA convention of effectively omitting biogenic carbon. Because any net additional $\mathrm{CO}_{2}$ uptake is tallied on the cropland and reflected as a credit on the overall ABC balance sheet, biogenic process emissions may be offset depending on the magnitude of net carbon uptake given by $\mathrm{M}_{\mathrm{in}}$. 
Table 4. Biorefinery carbon balance and on-site emissions

\begin{tabular}{|l|c|r|}
\hline & \multicolumn{2}{|c|}{ Metric tons of carbon per year $\left(\mathrm{t}_{\mathrm{c}} / \mathrm{yr}\right)$} \\
\hline (a) Itemized carbon balance & Notation & Year 1 \\
\hline Carbon embodied in feedstock & Min & $(188,075)$ \\
Carbon in ethanol & $M_{\text {ethanol }}$ & 87,022 \\
Carbon in $\mathrm{CO}_{2}$ from fermentation & Mloss & 43,511 \\
Carbon in coproducts & Mcoprod & 65,192 \\
\hline Balance error (output - input) & & 7,650 \\
\hline \hline (b) On-site $\mathrm{CO}_{2}$ emissions & & \\
\hline Fermentation & & 43,511 \\
Natural gas combustion & & 25,075 \\
\hline Total $\mathrm{CO}_{2}$ emissions from biorefinery & & $\mathbf{6 8 , 5 8 6}$ \\
\hline
\end{tabular}

$M_{\text {burn }}$ reflects biomass burned at the biorefinery for thermal energy or cogeneration. For example, if stover is harvested along with the grain and transported to a biorefinery to burn for process energy, then $\mathrm{M}_{\text {in }}$ will include the carbon in both the grain and stover and the $\mathrm{CO}_{2}$ emitted when burning the stover is tallied by $\mathrm{M}_{\text {burn. }}$. No such biomass was used at the IRE facility in 2007, and so this term is not used in our analysis.

$\mathrm{M}_{\text {loss }}$ includes $\mathrm{CO}_{2}$ released during fermentation. For ethanol production, one mole of $\mathrm{CO}_{2}$ is released per mole of $\mathrm{C}_{2} \mathrm{H}_{5} \mathrm{OH}$ produced and so, on a carbon mass basis, one $\mathrm{t}_{\mathrm{c}}$ is released in $\mathrm{M}_{\text {loss }}$ for each two $\mathrm{t}_{\mathrm{c}}$ embodied in the ethanol product. $\mathrm{M}_{\text {loss }}$ would be essentially zero for oilseed processing, e.g.,. for soy-based biodiesel.

A biorefinery's on-site GHG emissions from non-biomass-based process energy use are calculated by applying standard emissions factors to the data for on-site energy consumption. GHG emissions that occur at the facilities where purchased energy or other inputs are produced, rather than at the refinery itself, are handled as discussed in Section 3.4 below.

The IRE facility carbon balance is summarized in the first section of Table 4 as derived according to Equation (6) from input and output data given in the IRE report. The corn feedstock input of 20,450,000 bushels implies a carbon input $\left(\mathrm{M}_{\mathrm{in}}\right)$ of $188 \mathrm{kt}_{\mathrm{c}} / \mathrm{yr}$ (corresponding to the corn harvest carbon given in Table 2). Carbon in products exiting the biorefinery involves $87 \mathrm{kt}_{\mathrm{c}} / \mathrm{yr}$ of anhydrous ethanol and $65 \mathrm{kt} / \mathrm{yr}$ of co-products, including dried and wet distillers grains plus a small volume of liquid thin sillage. The $\mathrm{M}_{\text {loss }}$ line shows the $\mathrm{CO}_{2}$ from fermentation, which is precisely one-half the carbon mass in the ethanol. The calculated mass balance is not perfect; as shown by the balance error, the sum of the estimated amounts of carbon in the outputs exceeds 
that in the feedstock input by $4 \%$. This level of discrepancy is not of concern given the likely uncertainties in the underlying data.

The other GHG emissions at the biorefinery are those from the natural gas burned on site for steam generation and drying purposes. Those emissions were calculated from the reported site energy use to obtain the value shown in part (b) of Table 4. Combined with the biogenic $\mathrm{CO}_{2}$ from fermentation, the total on-site emissions at the biorefinery amount to about $69 \mathrm{kt} / \mathrm{yr}$ for the first year of operation, as listed on the last line of the table. That value is carried forward into the ethanol pathway tally given in Table 7 below.

\subsection{GHG analysis of farm and refinery inputs}

This portion of the analysis pertains to inputs other than biogenic carbon, including electricity and other purchased fuels, fertilizers, chemicals and other inputs consumed at farms, refineries and other major processing or handling sites within a fuel's physical supply chain. Transportation of feedstocks, other inputs and products is treated as service input, and so the emissions from trucks and other forms of transport to and from refineries and farms are also included here.

These parts of ABC analysis are again similar to conventional LCA and so readily draw upon published data. For electricity, for example, a fuel cycle emissions factor ${ }^{22}$ incorporates emissions from both power plant and upstream resource production (e.g., natural gas extraction, processing and transmission). Fertilizer and other purchased inputs are be treated similarly, with emissions calculated in proportion to the quantity of input used:

$$
\mathrm{G}_{\mathrm{p}}=\mathrm{k}_{\mathrm{p}} \mathrm{x}_{\mathrm{p}}
$$

where $\mathrm{G}_{\mathrm{p}}$ represents the upstream $\mathrm{GHG}$ emissions associated with a flow $\mathrm{x}_{\mathrm{p}}$ of some input $p$ to the farm or biorefinery and $\mathrm{k}_{\mathrm{p}}$ is an emission factor, e.g., from GREET or from EPA's analysis. The same approach is used for the petroleum fuel pathway using national average upstream GHG emission factors for gasoline and diesel, again incorporating emissions at the refinery as well as further upstream in the fuel supply chain. The resulting upstream GHG emissions are converted to a carbon mass equivalent basis, including the effects of non- $\mathrm{CO}_{2}$ greenhouse gases weighted by Global Warming Potential (GWP). ${ }^{23}$

Table 5 summarizes these results based on the facility-specific data from the IRE report. Fertilizer production accounts for a good portion of the off-site emissions both years. In Year 0, $49 \%$ of the acreage was growing soy, which requires lesser use of fertilizers and other inputs and so results in lower associated off-site emissions. In Year 1, biorefinery inputs dominate the 
Table 5. Farm and biorefinery off-site GHG emissions

\begin{tabular}{|l|r|r|}
\hline \multicolumn{3}{|c|}{ Metric tons per year on a carbon mass basis $\left(\mathrm{t}_{\mathrm{c}} / \mathrm{yr}\right)$} \\
\hline & Year 0 & Year 1 \\
\hline Fertilizer production & 5,001 & 8,266 \\
Farm electricity use & 264 & 264 \\
Biorefinery electricity use & 0 & 6,746 \\
Upstream emissions of purchased fuels & 438 & 10,429 \\
\hline Total off-site GHG emissions $\left(\mathrm{t}_{c} / \mathrm{yr}\right)$ & $\mathbf{5 , 7 0 4}$ & $\mathbf{2 5 , 7 0 6}$ \\
\hline
\end{tabular}

calculation and the larger portion of that reflects the upstream emissions associated with natural gas use. We assume that farm electricity use was the same in both years.

\subsection{Coproduct and other displacement effects}

Shifts in agricultural product production and consumption associated with biofuel production affect GHG emissions outside the direct fuel supply chain in numerous ways. Addressing these effects involves consequential analysis such as that performed by EPA for the RFS2 using interlinked models that represent economic interactions within the agricultural sector, with other sectors and across international borders. Most such effects are not modeled in an attributional LCA model such as GREET, which only credits co-product effects; for the LCFS, GREET is supplemented by economic modeling of broader consequential impacts.

The one substitution effect commonly treated in LCA models is the use of distillers grains to feed livestock, thereby replacing other feeds and avoiding their associated GHG emissions. This effect is applied as a coproduct credit in the LCA. In ABC accounting, however, the quantities of carbon embodied in grain or in coproducts such as DDGS are recorded as exports. (In this context, "export" simply means something that crosses the circumscribed system boundary, rather than referring to international trade.) Here we report the carbon exports as a remainder term in the mass balance. For $\mathrm{ABC}$ analysis at the national scale, such effects could be addressed by referencing prior modeling such as that done by EPA using FASOM and other models for the RFS regulatory analysis. Although not used in the ABC analysis, for the sake of reference we computed a coproduct credit for the IRE operation; it amounts to $5.9 \mathrm{kt}_{\mathrm{c}} / \mathrm{yr}$ and reflects DDGS replacing corn and soymeal for a generic cattle feeding operation. ${ }^{24}$ 
Table 6. Vehicle $\mathrm{CO}_{2}$ emissions

\begin{tabular}{|l|c|c|c|}
\hline & $\begin{array}{c}\text { Gasoline } \\
\text { (Year 0) }\end{array}$ & $\begin{array}{c}\text { Ethanol } \\
\text { (Year 1) }\end{array}$ & $\begin{array}{c}\text { Difference } \\
\text { (Year 0 - Year 1) }\end{array}$ \\
\hline Volume (million gallons) & 36.7 & 55.8 & \\
Lower heating value (MJ/gallon) & 122.5 & 80.5 & \\
$\mathrm{CO}_{2}$ emissions factor $(\mathrm{gCO} / \mathrm{MJ})$ & 72.8 & 71.2 & \\
\hline Tailpipe $\mathbf{C O}_{2}$ (carbon mass flow, $\left.\mathbf{t}_{\mathrm{c}} / \mathbf{y r}\right)$ & $\mathbf{8 9 , 2 8 7}$ & $\mathbf{8 7 , 2 9 4}$ & $\mathbf{1 , 9 9 4}$ \\
\hline
\end{tabular}

\subsection{End-use (motor vehicle) $\mathrm{CO}_{2}$ emissions analysis}

This part of the analysis is a straightforward calculation based on combustion chemistry. The $\mathrm{CO}_{2}$ emissions for all fuels are computed based on emissions factors for direct combustion, e.g., in $\mathrm{gCO}_{2} / \mathrm{MJ}$ on a lower heating value (LHV) basis. Because they are unlikely make a significant difference in the results, non- $\mathrm{CO}_{2}$ emissions are not estimated.

In general and using the subscript $f$ to distinguish distinct fuel products, direct vehicular $\mathrm{CO}_{2}$ emissions from end-use combustion in year $t$ are given by

$$
E_{v, t}=\Sigma_{f} E_{v f, t}
$$

where

$$
\mathrm{E}_{\mathrm{vf}, \mathrm{t}}=\mathrm{e}_{\mathrm{f}} \mathrm{Q}_{\mathrm{vf}, \mathrm{t}}
$$

with $\mathrm{e}_{\mathrm{f}}$ being the $\mathrm{CO}_{2}$ emissions factor for a given fuel product and $\mathrm{Q}_{\mathrm{ft}}$ being the quantity of the fuel product consumed in energy units. The change in emissions

$$
\Delta \mathrm{E}_{\mathrm{v}, \mathrm{t}}=\mathrm{E}_{\mathrm{v}, \mathrm{t}}-\mathrm{E}_{\mathrm{v}, \mathrm{t}-1}
$$

then represents the net effect on tailpipe $\mathrm{CO}_{2}$ emissions due to the change in mix of fuel products consumed. Because the direct $\mathrm{CO}_{2}$ emissions factors $\left(\mathrm{e}_{\mathrm{f}}\right.$ ) vary little among fuel products that substitute for one another, it is apparent that $\Delta \mathrm{E}_{\mathrm{t}}$ will be a small fraction of the emissions.

Equation (11) simply represents the difference in direct tailpipe $\mathrm{CO}_{2}$ emissions due to substituting the anhydrous ethanol for an energy-equivalent quantity of conventional gasoline. The resulting estimates are given in Table 6 based on fuel properties from GREET. ${ }^{25}$ It is immaterial whether ethanol is burned in a gasohol blend or in the form of E85; the tailpipe $\mathrm{CO}_{2}$ emissions effect is the same either way. The calculation is driven by the amount of neat ethanol produced in Year 1 at the IRE facility, and the resulting value for $\Delta \mathrm{E}_{\mathrm{v}}$ amounts to $2.2 \%$ lower tailpipe $\mathrm{CO}_{2}$ emissions when burning ethanol instead of gasoline. 


\subsection{Summation of pathway emissions}

The net impacts are calculated by summing the $\mathrm{CO}_{2}$ and other GHG flows calculated in the preceding sections, with all variables in units of carbon mass. The components of $\mathrm{ABC}$ accounting are additive and summarized by pathway (from feedstock carbon uptake to end-use fuel combustion emissions) in Table 7. A breakout of process emissions is shown in grey italics; their subtotal is added to the carbon balance plus vehicle emissions to yield the pathway totals. These sums are dominated by the carbon uptake on the farm land, as shown on the first line and is based on the results given in Table 2. As in that table, the sign convention shows flows into the atmosphere as positive and carbon uptake as a debit (negative emission).

In Year 0, the biomass pathway produces no fuel and so the net carbon uptake is matched by the carbon embodied in the harvest, which is exported to the food supply. The Year 0 fossil pathway is a traditional full fuel cycle estimate for gasoline. The lower section of the table sums the biomass and fossil pathways to give the combined system total for each year. The Year 0 fossil pathway emissions of $111 \mathrm{kt}_{\mathrm{c}} / \mathrm{yr}$ exceed the net uptake of $102 \mathrm{kt} / \mathrm{yr}$ for the biomass pathway, which is part of the same real-world physical system even though it is not producing ethanol in Year 0 . The result is combined system net GHG emissions of $9.7 \mathrm{kt} / \mathrm{yr}$, shown as the

Table 7. Summary of pathway and combined system ABC flows

\begin{tabular}{|c|c|c|c|c|}
\hline \multirow{3}{*}{$\begin{array}{l}\text { Exchange with the atmosphere } \\
\text { Emissions given as positive numbers } \\
\text { Carbon uptake given as negative (debit) }\end{array}$} & \multicolumn{4}{|c|}{ Carbon mass basis $\left(\mathrm{t}_{\mathrm{c}} / \mathrm{yr}\right)$} \\
\hline & \multicolumn{2}{|c|}{ Biomass pathway } & \multicolumn{2}{|c|}{ Fossil pathway } \\
\hline & Year 0 & Year 1 & Year 0 & Year 1 \\
\hline Carbon balance on cropland & $(118,615)$ & $(188,675)$ & & \\
\hline \multicolumn{5}{|l|}{ Process emissions } \\
\hline Farm operations & 11,395 & 20,614 & & \\
\hline Biorefinery & - & 68,586 & & \\
\hline Processing inputs & 5,704 & 25,706 & & \\
\hline Process emissions subtotal & 17,098 & 114,905 & \multicolumn{2}{|l|}{21,908} \\
\hline Vehicle emissions & - & 87,294 & \multicolumn{2}{|l|}{89,287} \\
\hline Totals by pathway & $(101,516)$ & 13,524 & \multicolumn{2}{|l|}{111,195} \\
\hline Carbon exported & 118,615 & 65,192 & & \\
\hline \multirow[t]{2}{*}{ Combined system totals } & \multicolumn{2}{|c|}{ Biomass and Fossil } & \multicolumn{2}{|l|}{ Change } \\
\hline & Year 0 & Year 1 & $(\mathrm{Y} 1-\mathrm{Y0})$ & \\
\hline Net GHG emissions impact $\left(t_{c} / y r\right)$ & 9,679 & 13,524 & 3,845 & \\
\hline
\end{tabular}


first entry in the last row of the table. In Year 1, no gasoline is supplied and so the fossil pathway is not active. The biomass pathway produces ethanol, which is burned in the vehicles instead of gasoline, plus the exported coproducts (no grain is exported in this case). The biomass pathway now results in net GHG emissions to the atmosphere of $13.5 \mathrm{kt} / \mathrm{yr}$, which is also the Year 1 combined pathway total.

The conclusion is that using corn ethanol results in about $4 \mathrm{kt}_{\mathrm{c}} / \mathrm{yr}\left(3,845 \mathrm{t}_{\mathrm{c}} / \mathrm{yr}\right)$ more GHG emissions than having the same area of cropland supply corn and soybeans while using gasoline. This increase is small relative to direct (tailpipe) emissions, amounting to $4.3 \%$ of the $89 \mathrm{kt}_{\mathrm{c}} / \mathrm{yr}$ released as $\mathrm{CO}_{2}$ from gasoline combustion. Even though these estimates are highly data-driven, it seems unlikely that the measurement errors in the input data and parameters would propagate to as small as a 5\% uncertainty level, and so this estimated GHG increase cannot be considered significant. Recall that the biorefinery carbon mass balance discrepancy given in Table 4 was nearly $8 \mathrm{kt}_{\mathrm{c}} / \mathrm{yr}$, and so by itself larger than the nominal increase calculated here.

The process emissions estimates made here are consistent with those from the GREET analysis; after subtracting biogenic $\mathrm{CO}_{2}$ emissions from fermentation and a coproduct credit, the $115 \mathrm{kt}_{\mathrm{c}} / \mathrm{yr}$ process emissions subtotal in Table 7 corresponds to $53 \mathrm{gCO}_{2} \mathrm{e} / \mathrm{MJ}$, slightly less than the $55 \mathrm{gCO}_{2} \mathrm{e} / \mathrm{MJ}$ result given by Mueller et al (2008a). Other published LCA values fall in a similar range, varying according to the particular farm and biorefinery technology, energy source and efficiency assumptions used. Wang et al (2007) estimated $69 \mathrm{gCO}_{2} \mathrm{e} / \mathrm{MJ}$ for typical U.S. corn ethanol at the time. The IRE plant reflects the natural gas dry mill technology typical of newer plants at the time and similar to the configuration for which Plevin \& Mueller (2008) estimated a CI of $56 \mathrm{gCO}_{2} \mathrm{e} / \mathrm{MJ}$. Efficiency improvements can reduce process emissions; Wang et al (2011) calculated a roughly $12 \%$ CI reduction for the best corn ethanol technology they examined compared to a typical natural gas dry mill. Estimates made for the RFS final rule assume ongoing process improvements and, excluding land-use change effects, amount to $46 \mathrm{gCO}_{2} \mathrm{e} / \mathrm{MJ}$ for U.S. corn ethanol by 2022, nearly $50 \%$ lower than the baseline gasoline CI of $93 \mathrm{gCO}_{2} \mathrm{e} / \mathrm{MJ}$ (EPA 2010a, p. 14788).

The ABC results tell a very different story than one told LCA. The previously published GREET estimate of $55 \mathrm{gCO}_{2} \mathrm{e} / \mathrm{MJ}$ represents a CI $40 \%$ lower than that of petroleum gasoline. ${ }^{26}$ Such a CI reduction would imply a substantial net GHG emissions reduction of $46 \mathrm{kt}_{\mathrm{c}} / \mathrm{yr}$ when substituting corn ethanol for petroleum gasoline instead of the (insignificant) $4 \mathrm{kt}_{\mathrm{c}} / \mathrm{yr}$ increase 
found here. Neither the ABC nor attributional LCA estimates address the consequences of the large displacement of biomass from the food system, which if included would result in a higher overall GHG emissions impact when using the biofuel. The carbon embodied in system exports $\left(119 \mathrm{kt}_{\mathrm{c}} / \mathrm{yr}\right.$ in corn and soybeans for Year 0 and $65 \mathrm{kt} / \mathrm{yr}$ in coproducts for Year 1 ) is metabolized and released to the atmosphere as $\mathrm{CO}_{2}$ in other locations. However, the reduction in exports cannot just be credited as an emissions reduction because the loss of crops supplied from the farms serving the facility would be largely made up through increased production in other locations, for which assessing the net effect entails complex consequential modeling. Although the system we examine is circumscribed, our ABC analysis addresses the fundamental question of whether the biofuel production itself offers an increase in carbon uptake sufficient to balance the essentially unchanged tailpipe $\mathrm{CO}_{2}$ emissions. We find that it does not.

\subsection{Sensitivity analysis}

The $\mathrm{ABC}$ results are strongly influenced by the increase in NEP as farmers shift from growing soybeans to growing corn to supply the ethanol plant. While such cropping shifts (or the absence thereof) have the largest influence on the results, changes in yield are also a factor. For a sensitivity analysis, we evaluate the following cases:
A. The same values as used in Table 7.
B. Corn-corn rotation, i.e., with no soy planted in Year 0.
C. Fixed yield but keeping the soy-corn rotation.
D. Both corn-corn rotation and fixed yield.

For these cases, the Year 1 results are fixed and differing assumptions are used for the crops grown in Year 0, yielding the values given in Table 8 (and as shown in Figure 2 of the Executive Summary). These sensitivity results highlight how the change in GHG emissions is dominated by the baseline carbon uptake on the farmland. That uptake depends on the mix of crops grown, which also influences production-related GHG emissions on the farms.

As previously noted, corn is a much more prodigious producer of harvestable biomass than soybeans. The gain in carbon uptake due to growing corn instead of soybeans is enough to nearly offset the increase in processing emissions associated with corn ethanol production. Thus, in the base case (Case A), net GHG emissions go up by $4 \mathrm{kt}_{\mathrm{c}} / \mathrm{yr}$, an increase of only $4 \%$ relative to emissions when using gasoline. 
Table 8. Sensitivity to different cropland baseline assumptions

\begin{tabular}{|c|c|c|c|c|}
\hline Baseline (Year 0 ) flows $\left(t_{c} / y r\right)$ by case: & A & B & $\mathbf{C}$ & D \\
\hline Carbon balance on cropland & $(118,615)$ & $(175,607)$ & $(122,139)$ & $(188,075)$ \\
\hline Farm operations & 11,395 & 20,614 & 11,395 & 20,614 \\
\hline Processing inputs & 5,704 & 8,531 & 5,704 & 8,531 \\
\hline Biomass pathway subtotals & $(101,516)$ & $(146,463)$ & $(105,040)$ & $(158,931)$ \\
\hline Combined system totals (Year 0) & 9,679 & $(35,268)$ & 6,155 & $(47,736)$ \\
\hline Net change in emissions (Year 1 - Year 0 ) & 3,845 & 48,792 & 7,369 & 61,260 \\
\hline Increase over baseline tailpipe $\mathrm{CO}_{2}$ emissions & $4 \%$ & $55 \%$ & $8 \%$ & $69 \%$ \\
\hline \multicolumn{5}{|c|}{$\begin{array}{l}\text { A. The base case } A B C \text { analysis as given in Table } 5 \text {. } \\
\text { B. Corn-corn rotation, i.e., with no soy planted in Year } 0 \text {. } \\
\text { C. Fixed yield increase but keeping the soy-corn rotation. } \\
\text { D. Both corn-corn rotation and fixed yield. }\end{array}$} \\
\hline
\end{tabular}

However, if the farms were planted with all corn in the year prior to ethanol production, then the baseline $\mathrm{CO}_{2}$ uptake would be much higher, differing only by changes in yield. This situation is represented by Case $\mathrm{B}$, with the cropland absorbing $48 \%$ more carbon than if nearly half the land were growing soybeans. Farm inputs (largely fertilizer for the corn) also increase and the net effect is a large increase in net GHG emissions, amounting to $49 \mathrm{kt}_{\mathrm{c}} / \mathrm{yr}$ as shown in Table 8. In this case, ethanol use causes significantly higher GHG emissions than gasoline use. Moreover, this large excess reflects only direct carbon flows, before considering displacement effects that inevitably induce even higher emissions overall.

Case $\mathrm{C}$ controls for yield while keeping the same soy-corn rotation as the base case. With such a baseline, the corn yield in Year 0 is assumed to be the same as in Year 1 instead of being lower and so the ethanol production does not benefit from a yield gain. This effect is much smaller than the crop rotation effect, resulting in the combined system having somewhat greater emissions than Case A.

The final case is for baseline crop and yield conditions that are the same as those when ethanol is produced. The harvest in Year 0 is then the same as in Year 1 as are the farm-related emissions and the net result is the substantial net GHG emissions increase of $61 \mathrm{kt}_{\mathrm{c}} / \mathrm{yr}$ shown for Case D in Table 8. Relative to tailpipe $\mathrm{CO}_{2}$ emissions, this amounts to nearly $70 \%$ higher direct GHG emissions when using corn ethanol rather than petroleum gasoline. 
These findings underscore the critical (but poorly recognized) principle that unless there is an increase in net carbon uptake on the land from which a biofuel feedstock is harvested, there is no potential for an offset of vehicle end-use emissions. The biofuel's inherently greater process emissions definitively swing the balance to a substantial increase in net GHG emissions even before displacement effects and ILUC come into play. Case D is the one most similar to the past decade's biofuel expansion in the United States, which has not shifted cropping nearly as much as the large soy-to-corn shift seen for first year of IRE facility production that was evaluated by Case A.

The implication is that, in the real-world of commercial feedstock production, biofuels are clearly not carbon neutral, and provide no offset of vehicle end-use $\mathrm{CO}_{2}$ emissions in the transportation sector. This failure to reduce $\mathrm{CO}_{2}$ emissions is not even mainly due to the biofuel's higher processing emissions, but rather due to the lack of a sufficient increase in the rate of net $\mathrm{CO}_{2}$ uptake needed to balance out the essentially unchanged tailpipe emissions plus any biogenic process $\mathrm{CO}_{2}$ emissions (which are quite large for ethanol production).

\section{Conclusion}

The analysis presented here represents a first-ever direct accounting of the GHG impact of substituting a biofuel for a fossil fuel. It was done at the facility level, drawing on published data for an operational corn ethanol facility along with data on the farming operations that serve it. The analysis is driven by measured farm and facility data, enabling a real-world comparison of the net GHG emissions impact of substituting corn ethanol for gasoline.

The study reveals the large role played by the changes in $\mathrm{CO}_{2}$ uptake on the cropland from which biofuel feedstock is harvested, underscoring the crucial importance of baseline assumptions when performing GHG emissions analysis. The results show no significant change in net GHG emissions from the direct fuel production and use system for an initial condition that involves a soy-corn rotation on nearly half the cropland serving the biorefinery. Because a direct emissions saving benefit in the circumscribed fuel production and use system is a threshold condition for any overall GHG reduction benefit, even before considering displacements (which serve only to raise overall emissions), the results show that corn ethanol does not measurably reduce GHG emissions relative to gasoline. This finding is supported by sensitivity analyses with 
varying baseline conditions, which show substantially higher GHG emissions if the cropland was already growing corn before the harvest was used for ethanol production.

Because this study is a first-ever application of the ABC method, which differs greatly from the LCA methods that have dominated transportation fuel analysis to date, further research and applications of the method to cases more extensive than a single facility are needed. Such work can both refine the method and examine its implications for energy and environmental systems analysis and public policy. In any case, this study provides a strong empirical result that not only undermines LCA modeling-based claims of a GHG reduction for the currently dominant form of commercial biofuel production, but also refutes the claim of biofuels' inherent carbon neutrality as commonly assumed to date. 


\section{ENDNOTES}

1 See https://greet.es.anl.gov/.

${ }^{2} \mathrm{CI}$ has also been termed global warming intensity (GWI), e.g., by CARB and others, reflecting how the associated models weight different GHG species by global warming potential (GWP) and may incorporate other effects to better approximate radiative forcing impacts; see, e.g., Farrell \& Sperling (2007).

${ }^{3}$ See, e.g., Farrell et al (2006) as well as more recent work such as Wang et al (2011) that claims to strengthen such findings in light of ethanol production efficiency improvements.

${ }^{4}$ EPA (2010a) at FR 75(58): 14788.

5 Plevin et al (2010); Mullins et al (2011).

6 DeCicco (2009); DeCicco (2012); McCarl (2008) also makes this point more obliquely.

7 Larson (2006); Gnansounou et al. (2008); Delucchi (2013).

8 DeCicco (2012) defines ABC accounting and discusses its rationale and key differences from LCA.

${ }^{9}$ EPA (2010b), pp. 466-67.

${ }^{10}$ Hertel et al (2010); Mosnier et al (2012); Rajagopal \& Plevin (2013).

${ }^{11}$ Schlamadinger et al (1997); see also Figure 7 in IEA (2010) and DeCicco (2015).

12 The information described here can be found in Chapter 5 of Schlesinger \& Bernhardt (2013) as well as in most basic ecology texts. Unit conversions are 1 metric ton per hectare (t/ha) $=100 \mathrm{~g} / \mathrm{m}^{2}=892 \mathrm{lbs} / \mathrm{acre}$.

${ }^{13}$ Technically, some of the carbon may end up elsewhere, e.g., entrained or dissolved in water running off of the land, but these quantities are generally small relative to the others and not addressed in this analysis.

${ }^{14}$ Lovett et al (2006).

${ }^{15}$ See, e.g., Kirschbaum \& Mueller (2001).

${ }^{16}$ DeCicco (2013).

${ }^{17}$ http://www.chsinc.com/energy-and-industrial/renewable-fuels/ethanol-production

${ }^{18}$ Energy equivalencies given on a lower heating value (LHV) basis using $80.5 \mathrm{MJ} / \mathrm{gal}$ for anhydrous ethanol, or 0.658 gallons of gasoline equivalent (gge) per gallon of ethanol.

${ }^{19}$ Mueller \& Kwik (2013); Wang et al (2012).

${ }^{20}$ Note that these small $\triangle$ SOC values are themselves highly uncertain given the very high general uncertainty of any soil carbon estimates.

${ }^{21}$ Mueller et al (2008b).

${ }^{22}$ For the case study, we used a northern Illinois regional emissions factor of $619 \mathrm{gCO}_{2} \mathrm{e} / \mathrm{kWh}(1.36 \mathrm{lb} / \mathrm{kWh})$ as given by EPA's eGRID database.

${ }^{23}$ Consistently with GREET 1.8 and subsequent editions, we assumed the IPCC 2007 100-year GWP values of 25 for $\mathrm{CH}_{4}$ and 298 for $\mathrm{N}_{2} \mathrm{O}$.

${ }^{24}$ Because Mueller et al (2008a) did not break out their coproduct credit, we used a displacement ratio given by Hill et al (2006), who estimated a DDGS credit amounting to $20.3 \%$ of the energy value (LHV) of the ethanol produced in a dry-mill facility. We multiplied the farm-only portion of the process carbon emissions calculated here by that fraction to obtain a coproduct credit of 5,913 $t_{c}$ for the Year 1 IRE operation.

${ }^{25}$ We used values tabulated in ORNL (2011), Appendix A, which were in turn based on GREET 1.8d.

${ }^{26}$ Mueller et al (2008a) give a IRE 2007 corn ethanol CI of $54.8 \mathrm{gCO}_{2} \mathrm{e} / \mathrm{MJ}$ compared to $92.1 \mathrm{gCO}_{2} \mathrm{e} / \mathrm{MJ}$ for gasoline based on GREET analysis. Multiplying the $37.3 \mathrm{gCO}_{2} \mathrm{e} / \mathrm{MJ}$ difference between those two values by the $4.495 \mathrm{PJ}$ energy value of the delivered fuel and converting from $\mathrm{CO}_{2}$ to carbon yields $46 \mathrm{kt}_{\mathrm{c}}$. 


\section{REFERENCES}

Clarke, S., \& Preto, F. 2011. Biomass burn caracteristics. Factsheet (June 2011). Retrieved from http://www.omafra.gov.on.ca/english/engineer/facts/11-033.htm

DeCicco, J.M. 2009. Addressing Biofuel GHG Emissions in the Context of a Fossil-Based Carbon Cap. Report prepared for the Environmental Defense Fund. Ann Arbor: University of Michigan, School of Natural Resources and Environment, October. http://hdl.handle.net/2027.42/76029

DeCicco, J.M. 2012. Biofuels and carbon management. Climatic Change 111(3): 627-640. http://dx.doi.org/10.1007/s10584-011-0164-Z

DeCicco, J.M. 2013. Biofuel's carbon balance: doubts, certainties and implications. Climatic Change 121(4): 801-814. http://dx.doi.org/10.1007/s10584-013-0927-9

DeCicco, J.M. 2015. The liquid carbon challenge: evolving views on transportation fuels and climate. WIREs Energy \& Environment 4(1): 98-114. http://dx.doi.org/10.1002/wene.133

Delucchi, M.A. 2013. Estimating the Climate Impact of Transportation Fuels: Moving Beyond Conventional Lifecycle Analysis Toward Integrated Modeling Systems and Scenario Analysis. Proc Wash Acad Sci, Fall: 43-66.

EPA. 2010a. Regulation of Fuels and Fuel Additives: Changes to Renewable Fuel Standard Program, Final Rule. Washington, DC: U.S. Environmental Protection Agency. Federal Register 75(58): 14669ff., March 26.

EPA. 2010b. Renewable Fuel Standard Program (RFS2) Regulatory Impact Analysis. Report EPA-420-R-10-006. Washington, DC: U.S. Environmental Protection Agency. February.

Eve, M. D., Sperow, M., Howerton, K., Paustian, K., \& Follett, R. F. (2002). Predicted impact of management changes on soil carbon storage for each cropland region of the conterminous United States. Journal of Soil and Water Conservation 57; 196-204.

Farrell, A.E., et al. 2006. Ethanol can contribute to energy and environmental goals. Science 311: 506-08.

Farrell, A.E., and D. Sperling. 2007. A Low-Carbon Fuel Standard for California, Part 1: Technical Analysis. Report UCD-ITS-RR-07-07. Davis, CA: University of California, Davis, Institute of Transportation Studies, August.

Gnansounou, E., et al. 2008. Energy and greenhouse gas balances of biofuels: biases induced by LCA modelling choices. $J$ Sci \& Ind Res 67: 885-897.

Hertel, T.W., et al. 2010. Effects of U.S. maize ethanol on global land use and greenhouse gas emissions: estimating market-mediated responses. Bioscience 60(3): 223-231. http://dx.doi.org/10.1525/bio.2010.60.3.8

Hill, J. et al. 2006. Environmental, economic, and energetic costs and benefits of biodiesel and ethanol biofuels. PNAS 103(30): 11206ff. http://dx.doi.org/10.1073/pnas.0604600103.

IEA. 2010. Bioenergy, Land Use Change and Climate Mitigation. Report for Policy Advisors and Policy Makers. IEA Bioenergy:ExCo:2010:03. Paris: International Energy Agency. 
Johnson, D.M. 2008. The 2007 Cropland Data Layer. USDA-NASS presentation slides. Washington, DC: United States Department of Agriculture, National Agricultural Statistics Service. http://www.farmfoundation.org/projects/documents/Johnson.pdf

Kim, Y., Mosier, N.S., Hendrickson, R., et al. 2008. Composition of corn dry-grind ethanol byproducts: DDGS, wet cake, and thin stillage. Bioresource Technology 99: 5165-76. http://dx.doi.org/10.1016/j.biortech.2007.09.028

Kirschbaum, M.U.F., and R. Mueller (eds.) 2001. Net Ecosystem Exchange. Canberra, Australia: Cooperative Research Centre for Greenhouse Gas Accounting. www.kirschbaum.id.au/NEE_Workshop_Proceedings.pdf

Larson, E.D. 2006. A review of lifecycle analysis studies on liquid biofuel systems for the transport sector. Energy for Sustainable Development X(2): 109-126.

McCarl, B. 2008. Lifecycle Carbon Footprint, Bioenergy and Leakage: Empirical Investigations. Farm Foundation Workshop on the Lifecycle Carbon Footprint of Biofuels, Miami, January.

Mosnier, A., et al. 2012. The Net Global Effects of Alternative U.S. Biofuel Mandates. Report NI-R-12-01. Durham, NC: Duke University, Nicholas Institute for Environmental Policy Solutions, January. http://www.nicholasinstitute.duke.edu/climate/policydesign/net-globaleffects-of-alternative-u.s.-biofuel-mandates

Mueller, S., et al. 2008a. The Global Warming and Land Use Impact of Corn Ethanol Produced at the Illinois River Energy Center. Report for Illinois Corn Marketing Board and Illinois River Energy. Chicago: Energy Resources Center, University of Illinois at Chicago. July. http://www.erc.uic.edu/assets/pdf/ire_gwi_study102208.pdf

Mueller, S., et al. 2008b. A Bottom-Up Assessment of Land Use Related to Corn Ethanol Production. Report for Illinois Corn Marketing Board. Chicago: Energy Resources Center, University of Illinois at Chicago. December. http://www.erc.uic.edu/assets/pdf/20081217.pdf

Mueller, S., and J. Kwik. 2013. 2012 Corn Ethanol: Emerging Plant Energy and Environmental Technologies. Chicago: Energy Resources Center, University of Illinois at Chicago. April.

Mullins, K.A., W.M. Griffin and H.S. Matthews. 2011. Policy implications of uncertainty in modeled lifecycle greenhouse gas emissions of biofuels. Env Sci \& Tech 45: 132-138.

ORNL. 2011. Biomass Energy Data Book, Edition 4. Report ORNL/TM-2011/446. Oak Ridge, TN: Oak Ridge National Laboratory. http://cta.ornl.gov/bedb/download.shtml

Plevin, R.J., et al. 2010. Greenhouse gas emissions from biofuels' indirect land use change are uncertain but may be much greater than previously estimated. Env Sci \& Tech 44(21): 801521.

Plevin, R.J., \& S. Mueller. 2008. The effect of $\mathrm{CO}_{2}$ regulations on the cost of corn ethanol production. Env Res Lett 3: 024003. http://dx.doi.org/10.1088/1748-9326/3/2/024003

Rajagopal, D., and R.J. Plevin. 2013. Implications of market-mediated emissions and uncertainty for biofuel policies. Energy Policy 56: 75-82. http://dx.doi.org/10.1016/j.enpol.2012.09.076 
Schlamadinger, B., et al. 1997. Towards a standard methodology for greenhouse gas balances of bioenergy systems in comparison with fossil energy systems. Biomass \& Bioenergy 13(6): 359-75.

Schlesinger, W., and E. Bernhardt. 2013. Biogeochemistry: An Analysis of Global Change, 3rd Edition. Boston: Academic Press.

Searchinger, T., et al. 2009. Fixing a critical climate accounting error. Science 326: 527-28.

Searchinger, T. 2010. Biofuels and the need for additional carbon. Env Res Lett 5, http://dx.doi.org/10.1088/1748-9326/5/2/024007

USDA. 2007. Ethanol Transportation Backgrounder, 30. Washington, DC: U.S. Department of Agriculture. http://dx.doi.org/10.9752/TS029.09-2007

Wang, M.Q., et al. 2007. Life-cycle energy and greenhouse gas emission impacts of different corn ethanol plant types. Env Res Lett 2:024001

Wang, M.Q., et al. 2011. Energy and greenhouse gas emission effects of corn and cellulosic ethanol with technology improvements and land use changes. Biomass \& Bioenergy 35(5): 1885-96.

Wang, M.Q., et al. 2012. Well-to-wheels energy use and greenhouse gas emissions of ethanol from corn, sugarcane and cellulosic biomass for US use. Env Res Lett 7: 045905. 